\title{
Solidification Cracking Susceptibility of Stainless Steels: New Test and Explanation
}

\author{
The susceptibility was evaluated by the Transverse Motion Weldability test \\ and explained based on the continuity of the grain-boundary liquid
}

BY K. LIU, P. YU, AND S. KOU

\begin{abstract}
The susceptibility of austenitic, ferritic, and duplex stainless steels to solidification cracking was evaluated by the new Transverse Motion Weldability (TMW) test. The focus was on austenitic stainless steels. 304L and 316L were least susceptible, 321 was significantly more susceptible, and 310 was much more susceptible. However, some 321 welds were even less susceptible than $304 \mathrm{~L}$ welds. These 321 welds were found to have much finer grains to better resist solidification cracking. Quenching 321 during welding revealed spontaneous grain refining could occur by heterogeneous nucleation. For 304L, 316L, and 310, a new explanation for the susceptibility was proposed based on the continuity of the liquid between columnar dendrites; a discontinuous, isolated liquid allows bonding between dendrites to occur early to better resist cracking. In $304 \mathrm{~L}$ and $316 \mathrm{~L}$, the dendrite-boundary liquid was discontinuous and isolated, as revealed by quenching. The liquid was likely depleted by both fast back diffusion into $\delta$-dendrites (body-centered cubic) and the $L+\delta+\gamma$ reaction, which consumed $L$ while forming $\gamma$. In 310, however, the dendrites were separated by a continuous liquid that prevented early bonding between them. Back diffusion into $\gamma$-dendrites (face-centered cubic) was much slower, and the $L+\delta+\gamma$ reaction formed little $\delta$. Quenching also revealed skeletal/lacy $\delta$ formed in $304 \mathrm{~L}$ and $316 \mathrm{~L}$ well after solidification ended; thus, skeletal/lacy $\delta$ did not resist solidification cracking, as had been widely believed for decades. The TMW test further demonstrated that both more sulfur and slower welding can increase susceptibility.
\end{abstract}

\section{KEYWORDS}

- Transverse Motion Weldability Test • Stainless Steels

- Solidification Cracking • Welding • Austenitic • Ferritic

- Duplex • $304 \cdot 310 \cdot 316 \cdot 321 \cdot 430 \cdot 2205$

\section{Introduction}

Stainless steels are widely used in chemical and power industries. Numerous investigations have shown they are susceptible to cracking during solidification (Refs. 1-9). Austenitic stainless steels that are more resistant to solidification cracking tend to have a fusion-zone microstructure that is not fully austenite $\gamma$. They also contain a small but significant amount ( $\geq 5 \%$ ) of lacy or skeletal $\delta$-ferrite (Refs. $1-3$ ). Consequently, it has been widely accepted for decades that the lacy/skeletal $\delta$ structure resists solidification cracking.

Depending on its composition, when a liquid austenitic stainless steel is cooled to solidify, the primary solidification phase (the dendrites that form from the liquid) can be either $\delta$-ferrite, which is body-centered cubic (bcc), or austenite $\gamma$, which is face-centered cubic (fcc). Usually, if the primary solidification phase is $\gamma$, the resultant fusion zone is almost fully $\gamma$ with little $\delta$. However, if the primary solidification phase is $\delta$, the resultant fusion zone tends to show a lacy/skeletal $\delta$ structure at room temperature. Thus, austenitic stainless steels that solidify with primary $\delta$ tend to be significantly less susceptible to solidification cracking than those that solidify with primary $\gamma$, as shown by Masumoto et al. (Ref. 4).

Shankar et al. (Ref. 3) summarized many factors that have been proposed to explain the benefits of having a small, but significant, amount of $\delta$-ferrite in the $\gamma$ matrix (Refs. 10-16). For instance, the irregular crack path caused by the presence of skeletal/lacy $\delta$ in the $\gamma$ matrix can arrest cracks. The lower interface energy of $\delta / \gamma$ than that of either $\gamma / \gamma$ or $\delta / \delta$ can resist cracking. The skeletal/lacy $\delta$ refines $\gamma$ and thus resists cracking. The large $\delta / \gamma$ interface area disperses sulfur (S) and phosphorus (P). The $\delta \rightarrow \gamma$ transformation reduces tensile stresses. Much more $S$ and $\mathrm{P}$ can dissolve in $\delta$, and less $S$ and $P$ are thus present at grain boundaries to cause cracking. Thermal stresses are reduced because $\delta$ is more ductile than $\gamma$ and because the thermal expansion of $\delta$ is less than that of $\gamma$. Homogenization of $S$ and 


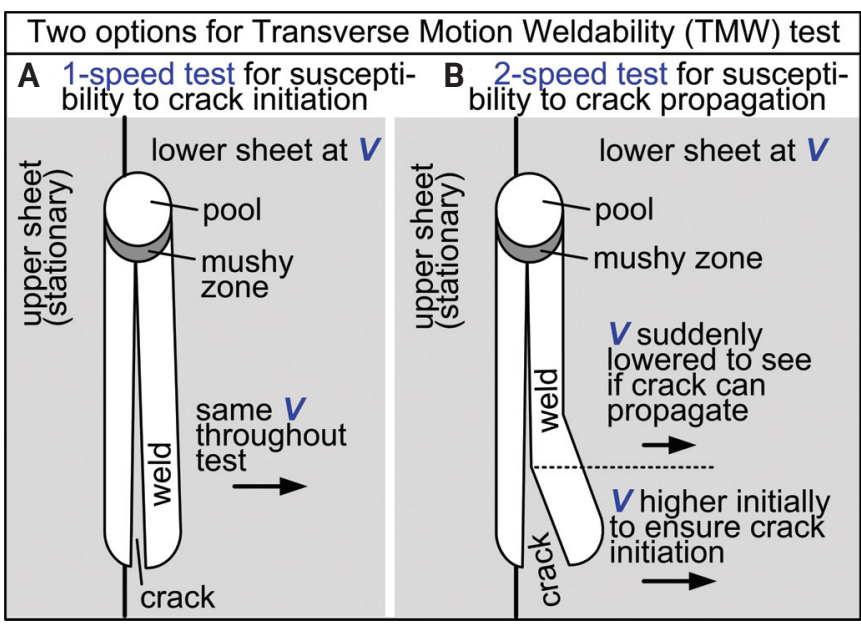

Fig. 1 - Two options of the TMW test: A - One-speed test for assessing susceptibility to crack initiation; $B-$ two-speed test for assessing susceptibility to crack propagation.

$\mathrm{P}$ is faster because of faster diffusion in $\delta$ bcc than in $\gamma \mathrm{fcc}$. Yu et al. (Ref. 17) quenched 304 stainless steel with Wood's metal (at $75^{\circ} \mathrm{C}$ ) during welding. In the mushy zone, the primary solidification phase $\delta$ and the $\gamma$ between $\delta$ were identified by electron backscatter diffraction (EBSD). Optical microscopy showed the lacy/skeletal $\delta$ structure did not exist in the mushy zone but in the fusion zone far behind the mushy zone.

Soysal and Kou (Refs. 18-20) recently developed the Transverse Motion Weldability (TMW) test to evaluate the susceptibility of $\mathrm{Al}$ alloys to solidification cracking. This is a simple lap welding process in which the lower sheet moves slowly in the transverse direction of welding to cause transverse tension in the mushy zone and hence solidification cracking. In the most widely used Varestraint test (Ref. 21), the workpiece is bent suddenly during welding to induce tension. Unlike the Varestraint test, the TMW test (Refs. 2, 18, 19) can do the following: 1) allows the use of filler metals to evaluate their significant effect on solidification cracking; 2) imposes deformation on the mushy zone alone instead of the whole workpiece; 3) imposes slow, instead of sudden, deformation (more realistic for welding); 4) separates crack initiation from crack propagation; 5) avoids liquation cracking and hence its interference with solidification cracking; 6) significantly reduces the cost of the apparatus; and 7) significantly reduces the amount of workpiece material required for testing.

The first purpose of the present study was to assess the susceptibility of various stainless steels to solidification cracking using the new TMW test. This is because the test has not yet been used for stainless steels, and it has several significant advantages over the most widely used Varestraint test. The second purpose was to explain why some austenitic stainless steels are more susceptible than others.

\section{Experimental Procedure}

The stainless steels used in the present study included austenitic stainless steels 304L, 316L, 321, and 310; ferritic stainless steel 430; and duplex stainless steel 2205. Their com-

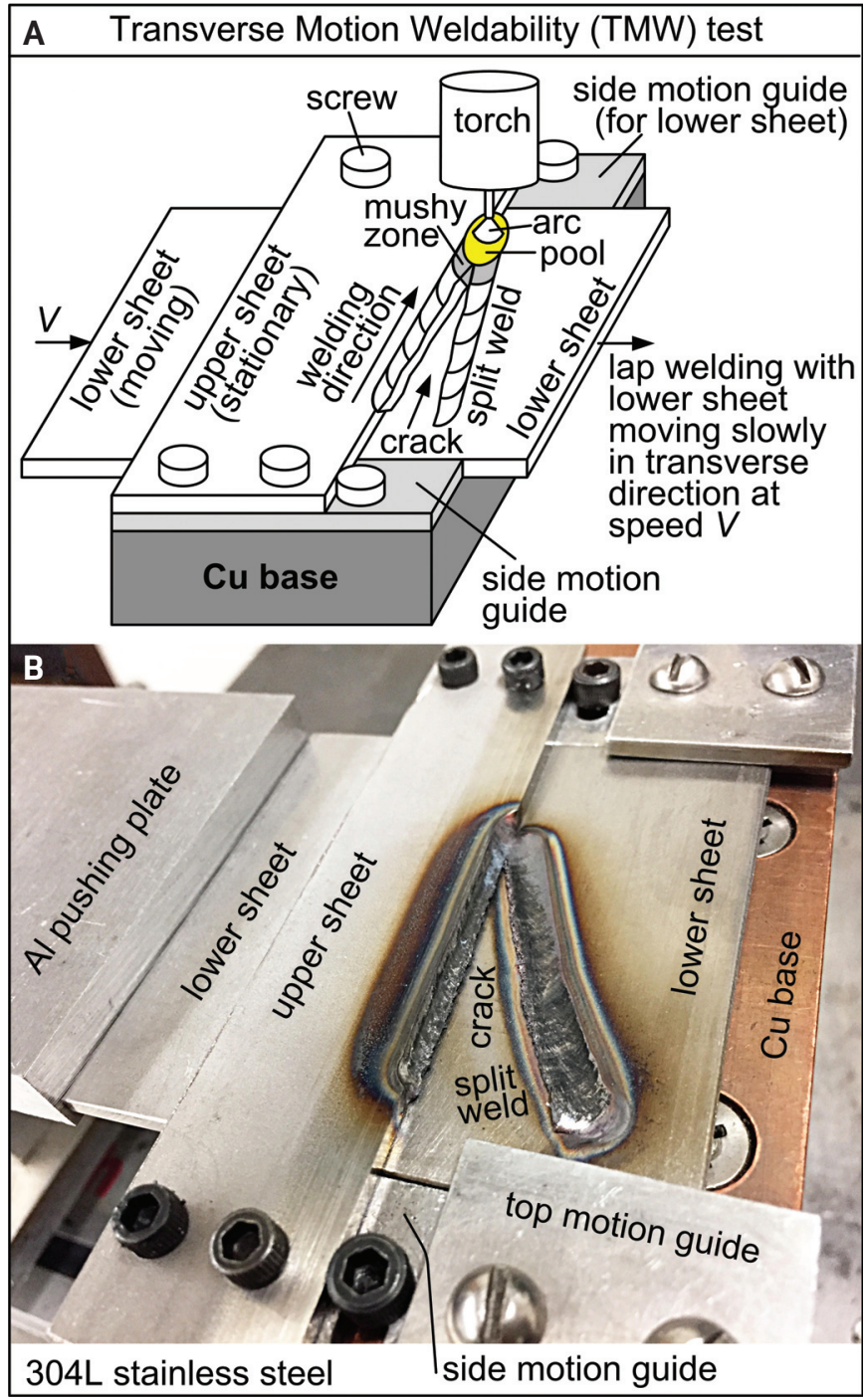

Fig. 2 - Example of a weld illustrating the TMW test: $A-$ Schematic (top motion guides not shown) (Refs. 18, 19); B $304 \mathrm{~L}$ stainless steel after being tested at $0.4 \mathrm{~mm} / \mathrm{s}$ lowersheet speed (initially $0.7 \mathrm{~mm} / \mathrm{s}$ ).

positions are shown in Table 1. Stainless steel 304L-A was higher in sulfur (0.014 wt-\%) than 304L-B, 304L-C, and 304-D (0.002 or $0.003 \mathrm{wt}-\%)$. The 321 was a stabilized-grade stainless steel with Ti added to form $\mathrm{TiC}$ instead of $\mathrm{Cr}_{23} \mathrm{C}_{6}$, which can lead to $\mathrm{Cr}$ depletion and hence corrosion along the grain boundaries in the heat-affected zone (HAZ) (Refs. 1, 2).

The upper sheet was $3.2 \mathrm{~mm}$ ( $1 / \%$ in.) thick, $25.4 \mathrm{~mm}$ ( 1 in.) wide, and $127 \mathrm{~mm}$ (5 in.) long. The lower sheet was $3.2 \mathrm{~mm}$ ( $1 / 1$ in.) thick, $76.2 \mathrm{~mm}$ (3 in.) wide, and $76.2 \mathrm{~mm}$ (3 in.) long. Before welding, the leading edge of the lower sheet stuck out beyond the upper sheet by $10 \mathrm{~mm}$. The surfaces near the expected welding path were polished to remove oxides and then cleaned with acetone.

To evaluate the susceptibility to solidification cracking, the TMW test (Refs. 18-20) was used. In the TMW test, a stationary upper sheet was lap welded to a lower sheet that moved slowly in the transverse direction of welding to induce transverse tension in the mushy zone and hence solidification cracking. To evaluate the susceptibility to crack 
Table 1-Compositions of Stainless Steels in wt-\%

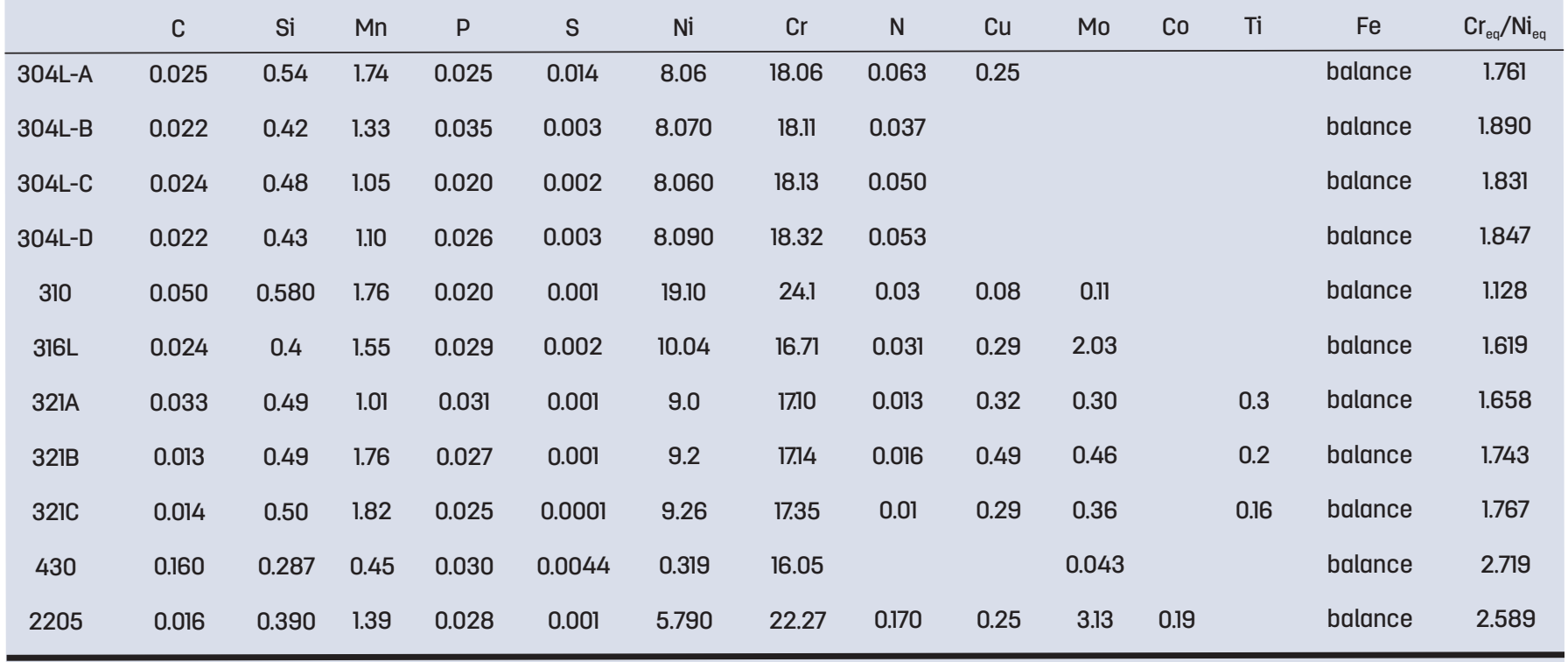

initiation, the one-speed option of the TMW test was used as illustrated in Fig. 1A. The lower sheet moved at a single, constant speed $(V)$ throughout the test. If the weld did not crack, the experiment was repeated at a higher $V$ to see if cracking would occur. To evaluate the susceptibility to crack propagation, however, the two-speed option was used as illustrated in Fig. 1B. The first speed of the lower sheet was set higher at $0.7 \mathrm{~mm} / \mathrm{s}$ to ensure crack initiation. After a short weld length of about $14 \mathrm{~mm}$, the lower sheet was suddenly slowed down to a second speed (e.g., 0.2 $\mathrm{mm} / \mathrm{s}$ ). If the crack did not propagate, the experiment was repeated at the same first speed and a higher second speed to see if the crack would propagate. A servo motor was programmed with the help of a computer to move an $\mathrm{Al}$ plate along a sliding stage and push the lower sheet.

Gas tungsten arc welding (GTAW) was conducted under the following conditions: 110-A welding current with the direct current electrode negative (DCEN) polarity, 10- to 11-V arc, $1.27-\mathrm{mm} / \mathrm{s}$ (3-in./min) welding speed (torch travel speed), $3.15 \times 10^{-4} \mathrm{~m}^{3} / \mathrm{s}\left(40 \mathrm{ft}^{3} / \mathrm{h}\right)$ Ar gas flow rate, and 3.2mm-diameter tungsten electrode with a 15-deg electrode-tip angle. The torch was inclined 20 deg toward the joint.

To initiate the TMW test, the servo motor was turned on to push the lower sheet, the arc was initiated $2 \mathrm{~s}$ afterward, the torch carriage was turned on $4 \mathrm{~s}$ afterward, the arc was extinguished $30 \mathrm{~s}$ afterward, and the carriage and the motor were then turned off to end the experiment.

The crack length was measured after each experiment. The normalized crack length was plotted against the lowersheet speed $V$. In the one-speed test, the normalized crack length equaled the crack length divided by the weld length. On the other hand, in the two-speed test, the normalized crack length equaled the crack length under the second speed divided by the weld length under the second speed. A transition range of the lower-sheet speed $V$ was identified, over which the normalized crack length increased from 0 (no crack) to 1 (full crack).

To help explain the results of the crack susceptibility tests, austenitic stainless steels 304L, 310, 316L, and 321 were quenched with Wood's metal $\left(75^{\circ} \mathrm{C}\right)$ during bead-on-plate welding. The workpiece was $102 \mathrm{~mm}$ (4 in.) long, $51 \mathrm{~mm}$ (2 in.) wide, and $1.6 \mathrm{~mm}$ (1/16 in.) thick. It was welded along the centerline in the length direction. This thinner workpiece allowed for more effective quenching than the workpiece for lap welding. DCEN was used with Ar shielding. The torch travel speed was 1.35 to $1.48 \mathrm{~mm} / \mathrm{s}$ (3.2 to $3.5 \mathrm{in} . / \mathrm{min}$ ), the welding current was 48 to $55 \mathrm{~A}$, and the voltage was 7.8 to $10 \mathrm{~V}$. The arc length was initially set at $2.3 \mathrm{~mm}$.

The resultant welds were cut, polished, and etched (Ref. 17). 304L and 316L were electrochemically etched with a solution consisting of $60 \mathrm{~g}$ of oxalic acid in $600 \mathrm{~mL}$ of water. The voltage was $10 \mathrm{~V}$ and the etching time was $15 \mathrm{~s}$. 310 was etched with mixed acids consisting of $10 \mathrm{~mL} \mathrm{HNO}_{3}, 20 \mathrm{~mL}$ $\mathrm{HCl}$, and $30 \mathrm{~mL} \mathrm{H}_{2} \mathrm{O}$. The etched samples were examined by optical microscopy - with or without differential interference contrast (DIC) - and scanning electron microscopy (SEM). EBSD was used to identify the phases present in the microstructure.

\section{Results}

Figure 2 shows an example of 304L after the TMW test. A schematic sketch of the TMW test (Refs. 18, 19) is also included as a reference. Figure 3 shows examples of the workpiece after the one-speed TMW test for crack initiation. For 316L, no cracking occurred at the lower-sheet speed of $0.25 \mathrm{~mm} / \mathrm{s}$, but cracking occurred all the way to the end at $0.30 \mathrm{~mm} / \mathrm{s}$. For 310 , full cracking occurred even at the relatively low speed of $0.15 \mathrm{~mm} / \mathrm{s}$, which indicated a higher crack susceptibility than 316L. On the other hand, for 304L, no cracking occurred even at $0.30 \mathrm{~mm} / \mathrm{s}$, thus indicating a lower crack susceptibility than 316L. Thus, Fig. 3 suggests the crack susceptibility decreased in the order of $310>316 \mathrm{~L}>304 \mathrm{~L}$.

Figure 4 shows examples of the 310 workpiece after the one- and two-speed TMW tests. The one-speed test in Fig. $4 \mathrm{~A}$ shows a crack that stopped shortly after initiation. The 


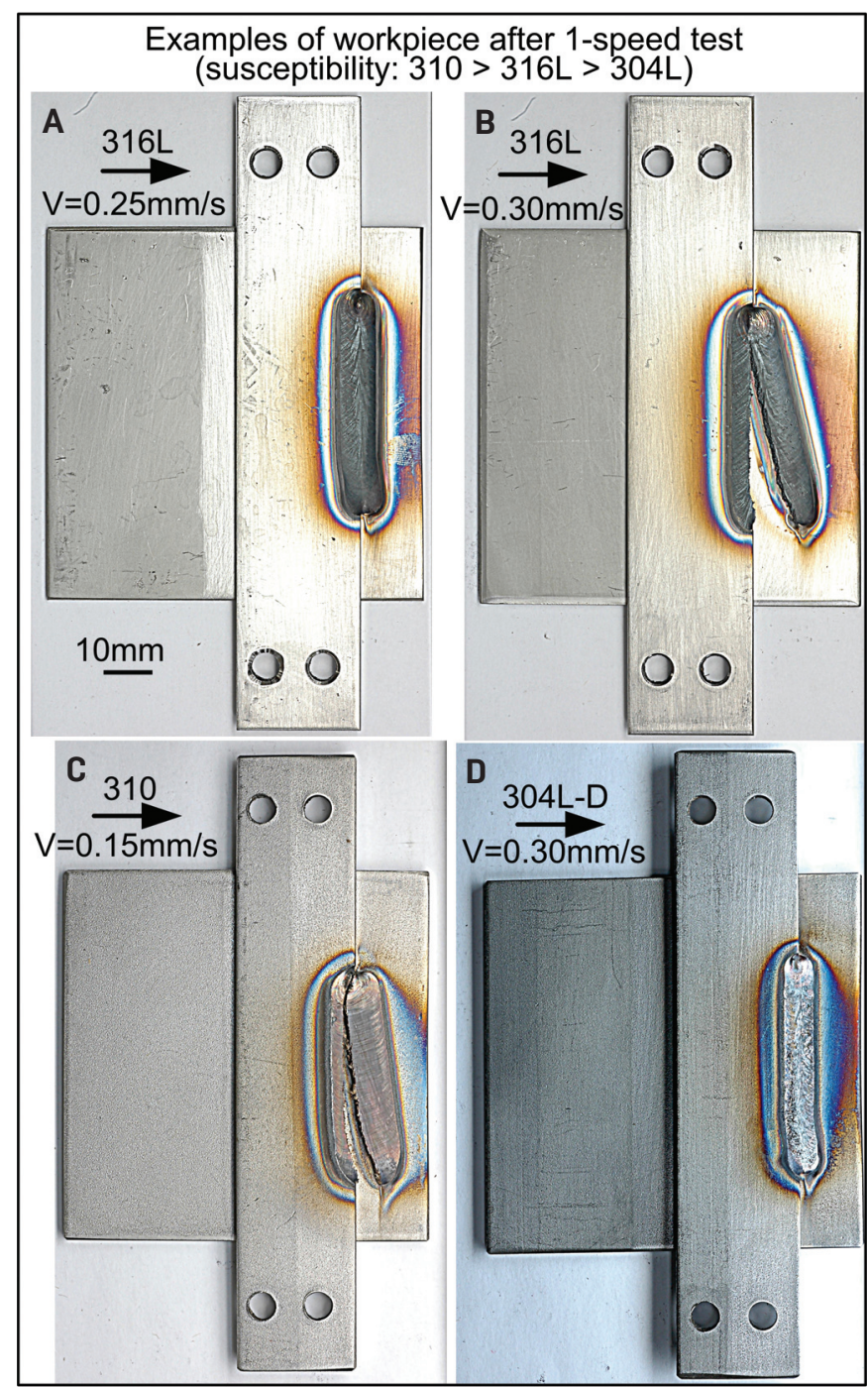

Fig. 3-Top views of the workpiece after the one-speed TMW test at various levels of lower-sheet speed V: A - 316L not cracked at $0.25 \mathrm{~mm} / \mathrm{s} ; \mathrm{B}-316 \mathrm{~L}$ cracked at $0.30 \mathrm{~mm} / \mathrm{s} ; \mathrm{C}-310$ cracked at $0.15 \mathrm{~mm} / \mathrm{s} ; \mathrm{D}-304 \mathrm{~L}-\mathrm{D}$ not cracked at $0.30 \mathrm{~mm} / \mathrm{s}$.

two-speed test in Fig. 4B shows a crack that stopped shortly after crack propagation had started. In both cases, the normalized crack length $\mathrm{L}_{\text {crack }} / \mathrm{L}_{\text {weld }}<1$. In both the one-speed test in Fig. 4C and the two-speed test in Fig. 4D, the normalized crack length $\mathrm{L}_{\text {crack }} / \mathrm{L}_{\text {weld }}=1$. The crack in the crater was excluded from $\mathrm{L}_{\text {crack }}$ or $\mathrm{L}_{\text {weld }}$.

Figure 5 shows the SEM image of the fracture surface of 304-C after the two-speed test. The first speed was 0.7 $\mathrm{mm} / \mathrm{s}$ and the second speed was $0.4 \mathrm{~mm} / \mathrm{s}$. The dendritic fracture surface confirmed the crack had been caused by solidification cracking (Ref. 2). In making this weld, an additional Ar shielding at $4.72 \times 10^{-4} \mathrm{~m}^{3} / \mathrm{s}\left(60 \mathrm{ft}^{3} / \mathrm{h}\right)$ behind the torch was used. This helped to clearly reveal the fracture surface by keeping it from becoming oxidized.

The results of the two-speed TMW test of 304L, 316L, and 310 are shown in Fig. 6A-C, with the normalized crack length plotted against the lower-sheet speed $V$. As shown, a transition range of $V$ existed between no cracking and full cracking. The level of $V$ at which the transition range existed decreased

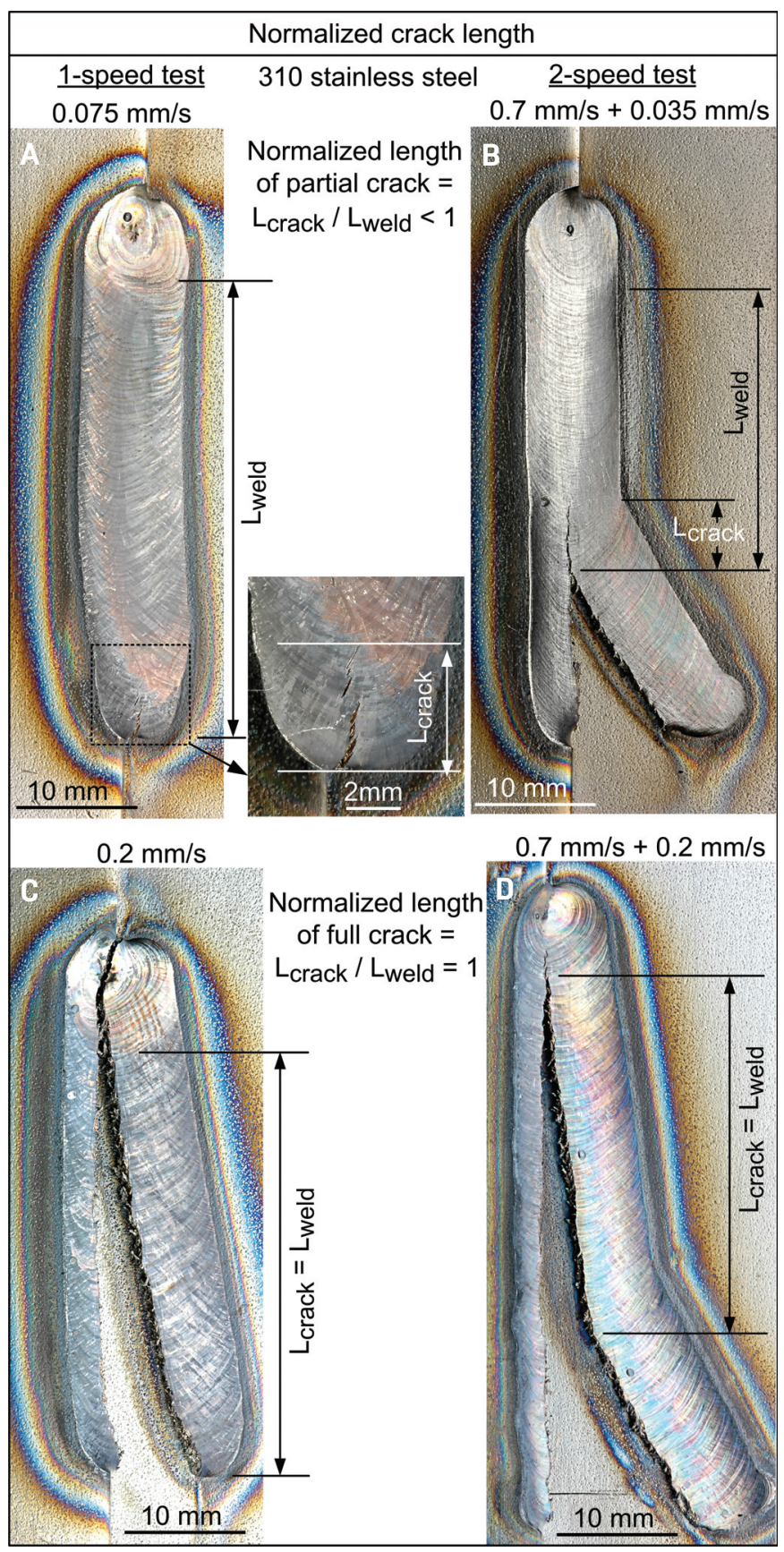

Fig. 4 - Close-up views of tested 310 welds showing normalized crack lengths: A - Partial crack after the one-speed test at $0.075 \mathrm{~mm} / \mathrm{s} ; \mathrm{B}$ - partial crack after the two-speed test at 0.7 and then $0.035 \mathrm{~mm} / \mathrm{s} ; \mathrm{C}$ - full crack after the onespeed test at $0.2 \mathrm{~mm} / \mathrm{s} ; \mathrm{D}-$ full crack after the two-speed test at 0.7 and then $0.2 \mathrm{~mm} / \mathrm{s}$.

in the order of 304L, 316L, and 310. The $V$ levels of the transition ranges of 304L and 316L were significantly higher than that of 310, suggesting that both 304L and 316L resist solidification cracking significantly better than 310 .

Figure 7 shows the results of the two-speed TMW tests of ferritic stainless steel 430 and duplex stainless steel 2205. The transition range of 430 appeared to be at a $V$ level slightly higher than that of 2205, suggesting 430 resists solidification cracking slightly better than 2205 . 


\section{Discussion}

\section{Consistency with Varestraint Test Results}

In the TMW test, the lower the $V$ level of the transition range, the easier it was for the motion of the lower sheet to cause solidification cracking and hence the higher the crack susceptibility became. The two-speed TMW test results shown in Figs. 6 and 7 are summarized in Fig. 8. $V$ was plotted upside down so the highest crack susceptibility was near the top of the plot just like the highest crack length was near the top for the most crack-susceptible alloy in the Varestraint test. Figure 8 shows the transition range was at the lowest $V$ level for 310 and highest for 304L and 316L, i.e., the crack susceptibility was the highest for 310 and lowest for 304L and 316L. The crack susceptibility decreased in the order of $310>2205>430$ $>316 \mathrm{~L}>304 \mathrm{~L}-\mathrm{C}$.

Based on the WRC-1992 diagram (Ref. 22), the $\mathrm{Cr}$ equivalent was defined as $\mathrm{Cr}_{\mathrm{eq}}=\mathrm{wt}-\% \mathrm{Cr}+\mathrm{wt}-\% \mathrm{Mo}+0.7$ (wt-\% $\mathrm{Nb})$. The Ni equivalent was defined as $\mathrm{Ni}_{\text {eq }}=w \mathrm{t}-\% \mathrm{Ni}+35$ $(w t-\%$ C) $+20($ wt-\% N) $+0.25($ wt-\% Cu). In Table 1, the $\mathrm{Cr}_{\text {eq }} / \mathrm{Ni}_{\text {eq }}$ ratio was calculated using these formulas for each stainless steel based on its composition. In Fig. 9, the transition range of $V$ for each stainless steel in Fig. 8 was plotted against its $\mathrm{Cr}_{\mathrm{eq}} / \mathrm{Ni}_{\mathrm{eq}}$ ratio. The curve of the crack susceptibility vs. $\mathrm{Cr}_{\mathrm{eq}} / \mathrm{Ni}_{\text {eq }}$ based on the Varestraint data (Ref. 1) was also included in Fig. 9 for comparison. As shown, the relative crack susceptibility based on the transition range of $V$ in the TMW test for crack propagation was consistent with the relative crack susceptibility based on the Varestraint test data. This suggests the TMW test can be applied to stainless steels to evaluate their susceptibility to solidification cracking. As mentioned previously, however, the TMW test has several significant advantages over the Varestraint test (Ref. 21).

\section{Microstructure and Crack Resistance}

Figure 10A shows the results of the two-speed TMW test on 321A. The transition range of $V$ was $0.13-0.20$

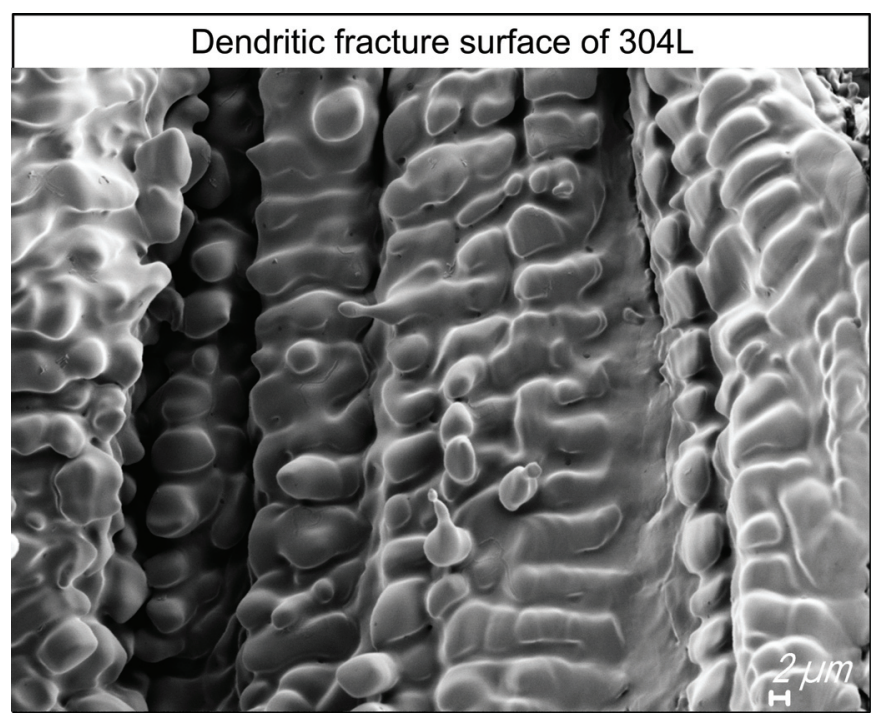

Fig. 5 - SEM image showing the dendritic fracture surface of 304L-C, which confirms solidification cracking.

$\mathrm{mm} / \mathrm{s}$. When the one-speed TMW test was to be conducted for comparison, 321A was already used up. The additional material available, i.e., 321B, differed from 321A slightly in composition. As shown in Table 1, 321A contained 0.013 wt-\% $\mathrm{N}$ and $0.3 \mathrm{wt}-\% \mathrm{Ti}$, and $321 \mathrm{~B}$ contained $0.016 \mathrm{wt}-\%$ $\mathrm{N}$ and $0.2 \mathrm{wt}-\% \mathrm{Ti}$. The slightly higher Ti content of 321A was probably required to match its slightly higher $C$ content, i.e., to tie up $\mathrm{C}$ in the $\mathrm{HAZ}$ as $\mathrm{TiC}$ so that no $\mathrm{Cr}_{23} \mathrm{C}_{6}$ would form to cause grain-boundary corrosion (Refs. 1, 2). Figure 10B shows the results of the one-speed TMW test of $321 B$. The transition range of $V$ was $0.34-0.35 \mathrm{~mm} / \mathrm{s}$, which was much higher than that of 321A (0.13-0.20 $\mathrm{mm} / \mathrm{s}$ ) and, in fact, even higher than that of 304LC $(0.27-0.325 \mathrm{~mm} / \mathrm{s}$, as shown previously in Fig. 6A). Thus, the crack susceptibility of $321 \mathrm{~B}$ was much lower than that of 321A and even lower than that of 304LC, as shown in Figs. 10C-D and 8. These results were surprising.

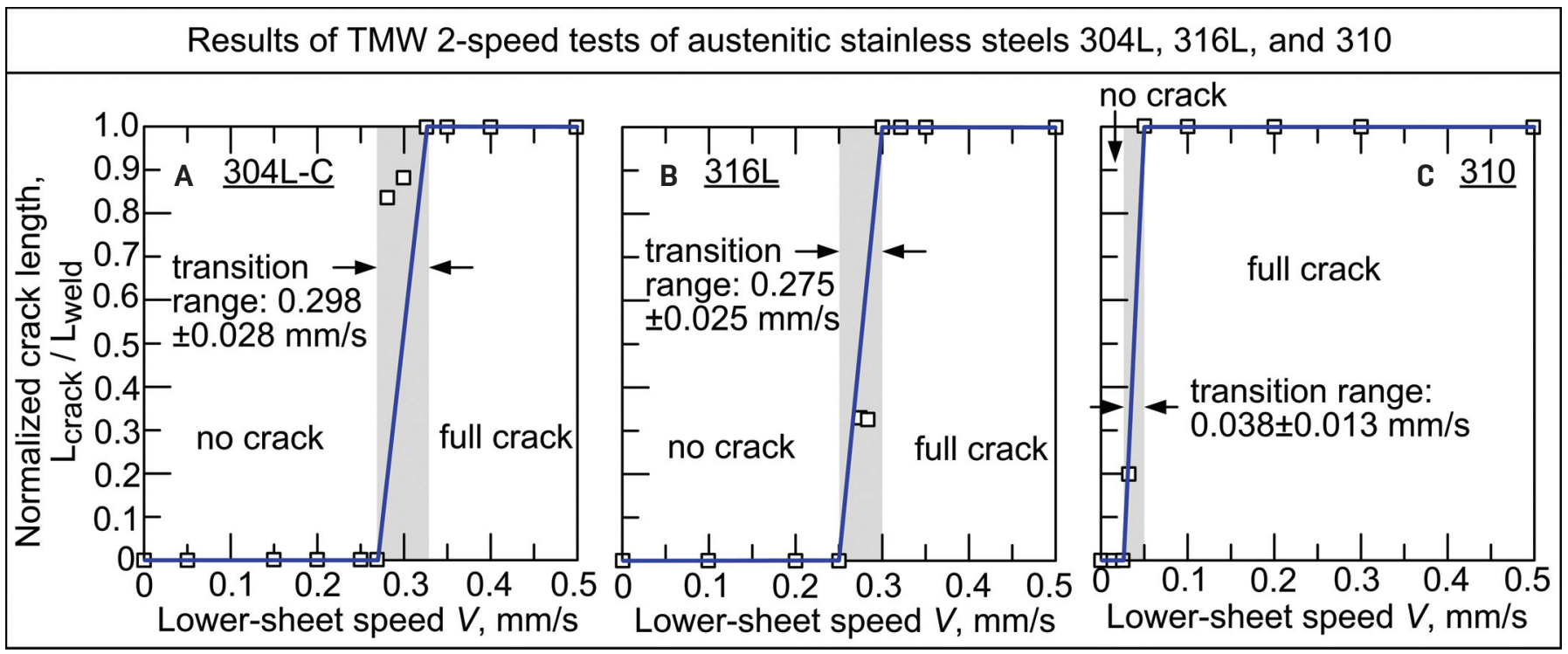

Fig. 6-Results of the TMW two-speed tests of austenitic stainless steels: A - 304L; B - 316L; C - 310. 


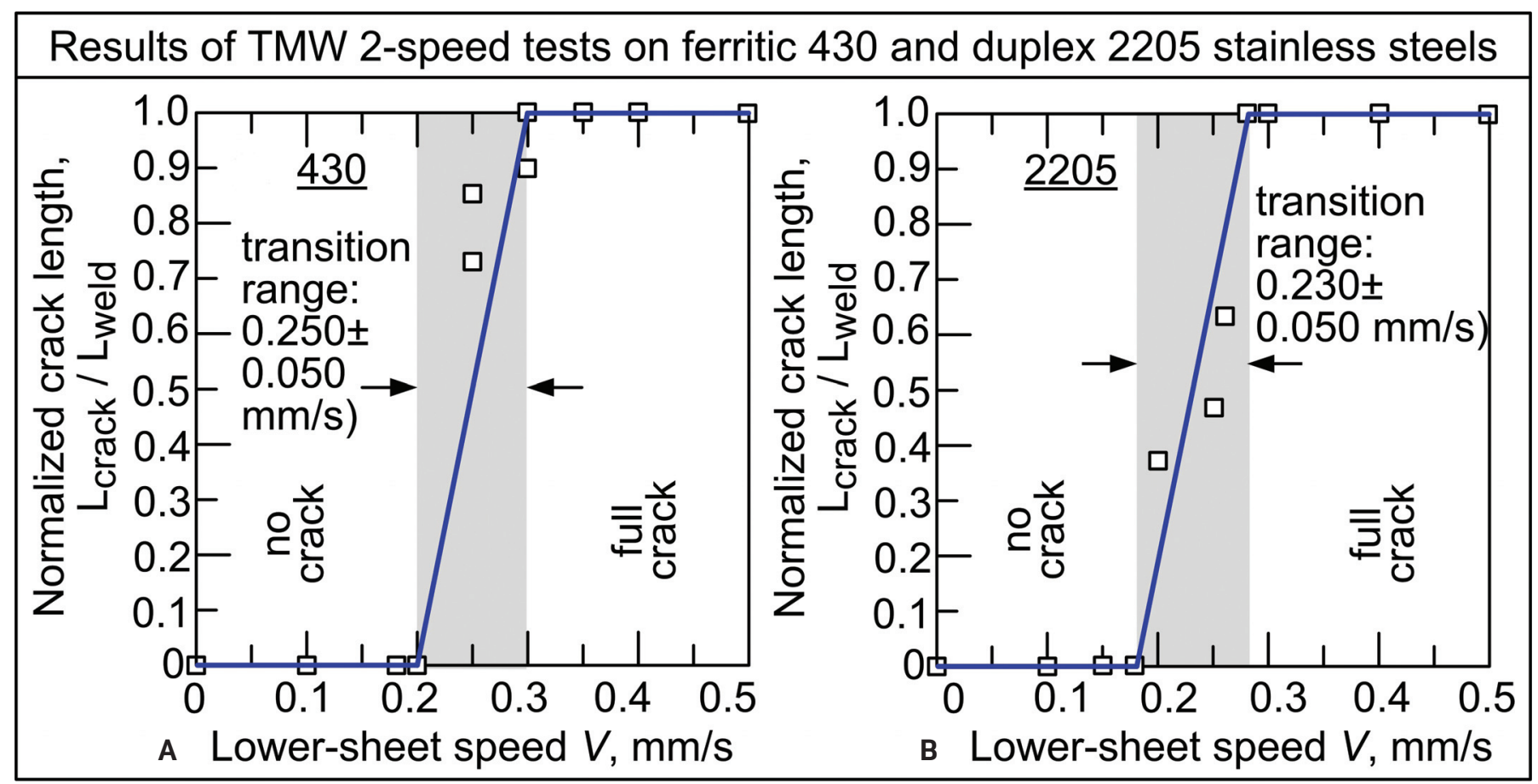

Fig. 7-Results of the two-speed TMW test: A - Ferritic stainless steel 430; B - duplex stainless steel 2205.

Although 321A was tested with the two-speed TMW test and 321B was tested with the one-speed TMW, the test results shown in Fig. 10 were not believed to be affected significantly by the difference between the two versions of the TMW test. As will be shown later in this research, the results of the one-speed test were similar to those of the two-speed test. Thus, the much lower crack susceptibility of 321B than 321A was likely to be real. As shown in Table $1, \mathrm{Cr}_{\mathrm{eq}} / \mathrm{Ni}_{\mathrm{eq}}=1.658$ for $321 \mathrm{~A}$ and 1.743 for $321 \mathrm{~B}$. As indicated by the Varestraint test curve in Fig. 9, the crack susceptibility did not change much between $\mathrm{Cr}_{\text {eq }} / \mathrm{Ni}_{\text {eq }}=1.5$ and $\mathrm{Cr}_{\mathrm{eq}} / \mathrm{Ni}_{\mathrm{eq}}=2.0$. Thus, the small difference between $\mathrm{Cr}_{\text {eq }} / \mathrm{Ni}_{\text {eq }}=1.658$ for $321 \mathrm{~A}$ and $\mathrm{Cr}_{\text {eq }} / \mathrm{Ni}_{\text {eq }}=1.743$ for $321 \mathrm{~B}$ could not be the reason for the much lower crack susceptibility of $321 \mathrm{~B}$.

To find out why $321 \mathrm{~B}$ was much less susceptible to solidification cracking than 321A, their lap welds were cut vertically along the welding direction near the centerlines of the welds. The welds made without moving the lower sheet were selected because the longitudinal vertical cross sections could be prepared without interference from cracks.

The fusion-zone microstructure of 321A is shown in Fig. 10E. Coarse, long, columnar grains grew along the welding direction and upward toward the top of the weld. As shown in Fig. 10F, fine equiaxed grains were present in the fusion zone of 321B, much finer than those in 321A. The enlarged micrographs in Fig. 10G and F again show the striking microstructural difference between the two 321 stainless steels. Both lacy $\delta$ and skeletal $\delta$ were visible in the fusion zone, the latter of which was easier to see in 321A.

To sum up, significant grain refining was evident in 321B, and it significantly reduced the crack susceptibility. Grain refining is known to reduce the susceptibility to solidification cracking (Ref. 2). A semisolid with fine equiaxed grains can better rearrange the grains to accommodate tensile strains without cracking (Ref. 23). It can also have a greater grainboundary area to distribute and dilute harmful impurities (S and P) or low-melting segregates (Ref. 2). However, it is unclear how fine grains formed in 321B. To answer the question, quenching was conducted during welding. A 1.6-mm-thick sheet was selected because quenching can be effective in beadon-plate welding of a thin sheet. Additionally, the weld pool can be pushed out and the sheet can be rapidly cooled by liquid Wood's metal. The material 321C contained 0.01 wt- $\% \mathrm{~N}$ and 0.16 wt-\% Ti, as shown in Table 1 . It had a $\mathrm{Cr}_{\mathrm{eq}} / \mathrm{Ni}_{\mathrm{eq}}=1.767$, which is very close to that of $\mathrm{Cr}_{\mathrm{eq}} / \mathrm{Ni}_{\mathrm{eq}}=1.743$ for 321B.

Figure 11 shows the evidence of equiaxed dendritic grains growing in the mushy zone of 321C. Particles appeared to be present within the equiaxed grains (indicated by arrows). They are likely $\mathrm{TiN}$ particles. Equiaxed grains have been shown to nucleate from TiN particles in GTAW of ferritic stainless steels containing $\mathrm{N}$ and Ti (Refs. 24, 25). For instance, Koseki et al. (Ref. 25) showed (by quenching with liquid $S n$ during welding) equiaxed grains grew from the TiN nuclei in a Fe-19Cr-2Mo-0.19Ti$0.0162 \mathrm{~N}$ ferritic stainless steel. They showed coarse columnar grains in GTAW of Fe-17Cr-0.007Ti-0.0097N but fine equiaxed grains in $\mathrm{Fe}-17 \mathrm{Cr}-0.3 \mathrm{Ti}-0.0092 \mathrm{~N}$.

In this study, an attempt was made to measure the composition of the particles, such as those inside the equiaxed grains in Fig. 11B. However, no significant Ti was found because TiN particles already dissolved in the acid solution during etching. Only larger particles that still remained showed significant Ti.

To still verify that TiN can form in $321 \mathrm{~B}$, its solidification path was calculated based on its exact composition in Table 1. The thermodynamics software Pandat ${ }^{\mathrm{TM}} 2019$ (Ref. 26), the iron-alloy database PanFe 2019 (Ref. 27), and the Scheil solidification model (Ref. 2) were used. As shown in 


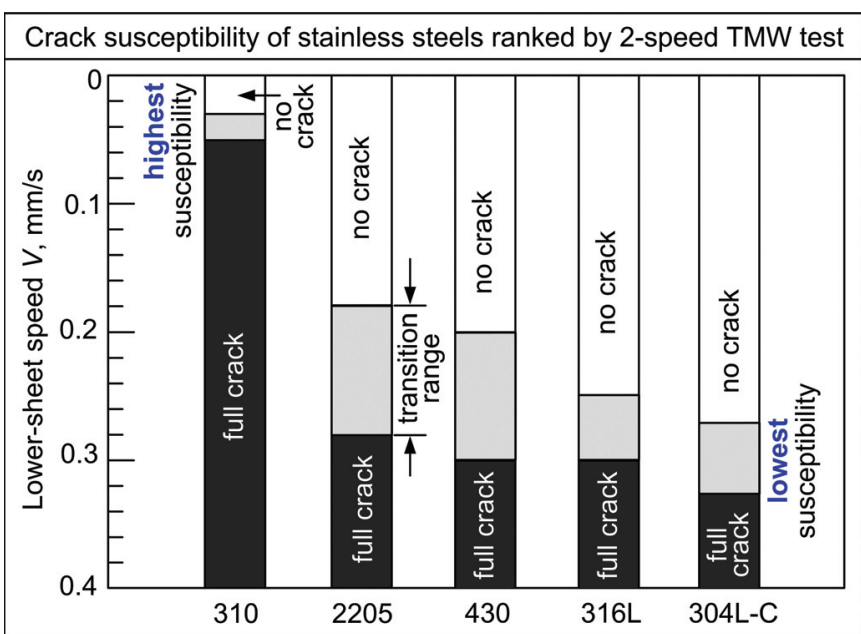

Fig. 8 - Summary of the two-speed TMW test results in Figs. 6 and 7.310 is most susceptible because even a very slow $V$ (e.g., $0.05 \mathrm{~mm} / \mathrm{s}$ ) can make it crack. The transition range of $\mathrm{V}$ increases; hence, crack susceptibility decreases in the order of $310>2205>430>316 L>304 L-C$.

Fig. 12A, TiN precipitated from the liquid, which can serve as the heterogeneous nuclei for $\delta$-ferrite to nucleate and grow into equiaxed grains. The solidification path was also calculated for 321B without N, as shown in Fig. 12B. There were no solid precipitates from the liquid before $\delta$ started to form.

It seems reasonable to expect grain refining in 321 when there are more $\mathrm{N}$ and $\mathrm{Ti}$ available to form TiN precipitates as potential nucleation sites. However, grain refining may depend not only on the chemical composition but also the welding conditions. For instance, grain refining did not occur in lap welding of 3.2-mm-thick 321A, but it occurred in bead-on-plate welding of $1.6-\mathrm{mm}$-thick $321 \mathrm{C}$ even though $\mathrm{N}$ and $\mathrm{Ti}$ were both less in 321C.

\section{Crack Initiation and Propagation}

The results of the one-speed test of 304L-D, 316L, and 310 are shown in Fig. 13. As shown in Table 1, 304L-C and 304L-D were very close in composition. The transition range increased in the order of 310, 316L, and 304L-D, with 304L-D and 316L being significantly higher than 310 . The one- and two-speed TMW test results of 310, 316L, and 304L in Figs. 6 and 13 are summarized in Fig. 14. It shows the one-speed test results were similar to the two-speed test results. This suggests the susceptibility of these austenitic stainless steels to the initiation of solidification cracking is similar to that of the propagation of solidification cracking. Both tests showed the crack susceptibility decreased in the order of $310>316 \mathrm{~L}>304 \mathrm{~L}$, which is consistent with the results of Arata et al. (Ref. 28) and Senda et al. (Ref. 29) based on the Varestraint test.

316 stainless steel is known to cover a fairly wide range of the Ni content; the more $\mathrm{Ni}$ that is present, the higher the solidification cracking susceptibility tends to be. As can be seen in Fig. 14A and B, both the one- and two-speed TMW tests showed the crack susceptibility of 304L and 316L were much lower than that of 310. In Fig. 14C, however, the crack susceptibility of 316L was significantly higher

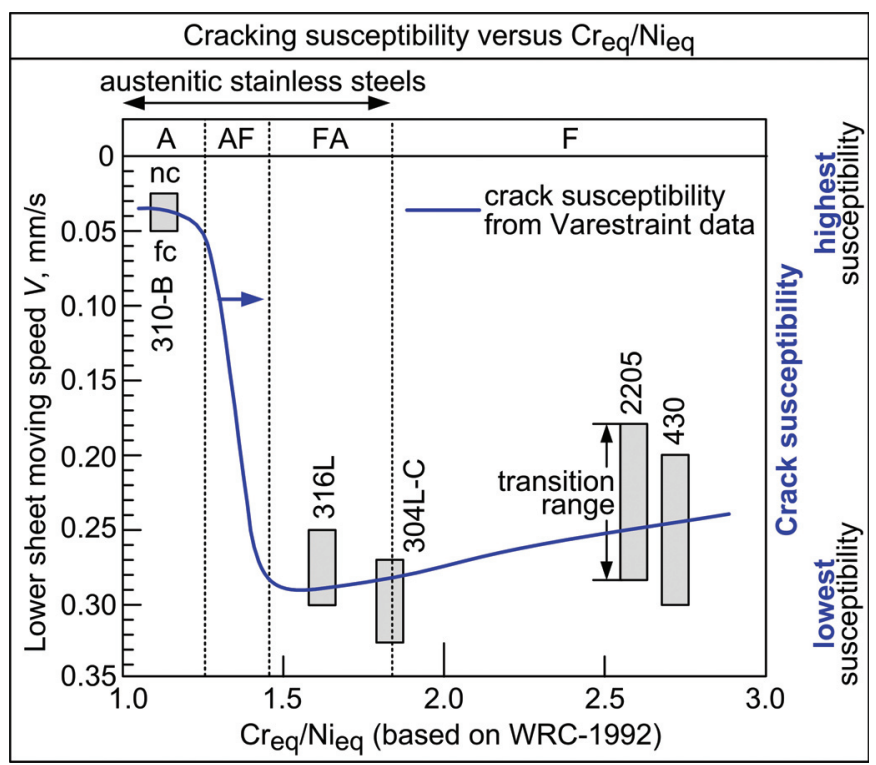

Fig. 9-Susceptibility of stainless steels as a function of $\mathrm{Cr}_{\text {eq }} / \mathrm{Ni}_{\text {eq }}$ with $\mathrm{Cr}$ equivalent $\mathrm{Cr}_{\text {eq }}$ and $\mathrm{Ni}$ equivalent $\mathrm{Ni}_{\text {eq }}$ defined by WRC-1992 (Ref. 22). The curve is based on data from the Varestraint test (Ref. I).

than that of 304L though still not close to that of 310. This is likely because the Ni content in 316L was significantly higher in the study of Arata et al. (Ref. 28), i.e., $15.1 \mathrm{wt}-\%$, and in the study of Senda et al. (Ref. 29), i.e., $13.0 \mathrm{wt}-\%$, than in the present study (10.0 wt-\%).

\section{New Explanation for Susceptibility}

A new explanation for the susceptibility of austenitic stainless steels to solidification cracking is proposed as follows based on the continuity of the liquid between columnar dendrites in the mushy zone. If the liquid is continuous, columnar dendrites are separated from each other everywhere; thus, it is easy for tension (induced by welding) to pull them apart to cause solidification cracking. However, if the liquid is depleted to become discontinuous and isolated, columnar dendrites can bond to each other early to resist cracking at locations where no liquid exists. No matter if the bonding is $\delta$ to- $\delta$, $\gamma$-to- $\gamma$, or $\delta$-to- $\gamma$, a solid bridge between dendrites is much stronger than a liquid bridge. Thus, the susceptibility can be much lower if the liquid between columnar dendrites is depleted to become discontinuous and isolated. As shown in the next three sections, this depletion of dendrite-boundary liquid can be more significant in primary- $\delta$ solidification, such as with $304 \mathrm{~L}$ and $316 \mathrm{~L}$, than in primary $-\gamma$ solidification, such as with 310 .

\section{L Microstructure and Crack Resistance}

To reveal the liquid along the boundaries between columnar dendrites in the mushy zone, quenching during beadon-plate welding was conducted on a single $1.6-\mathrm{mm}$ sheet as previously described. Quenching can reveal the elevatedtemperature microstructure during welding. The vast majority of studies on solidification cracking in stainless steels were based on the room-temperature microstructure of the 


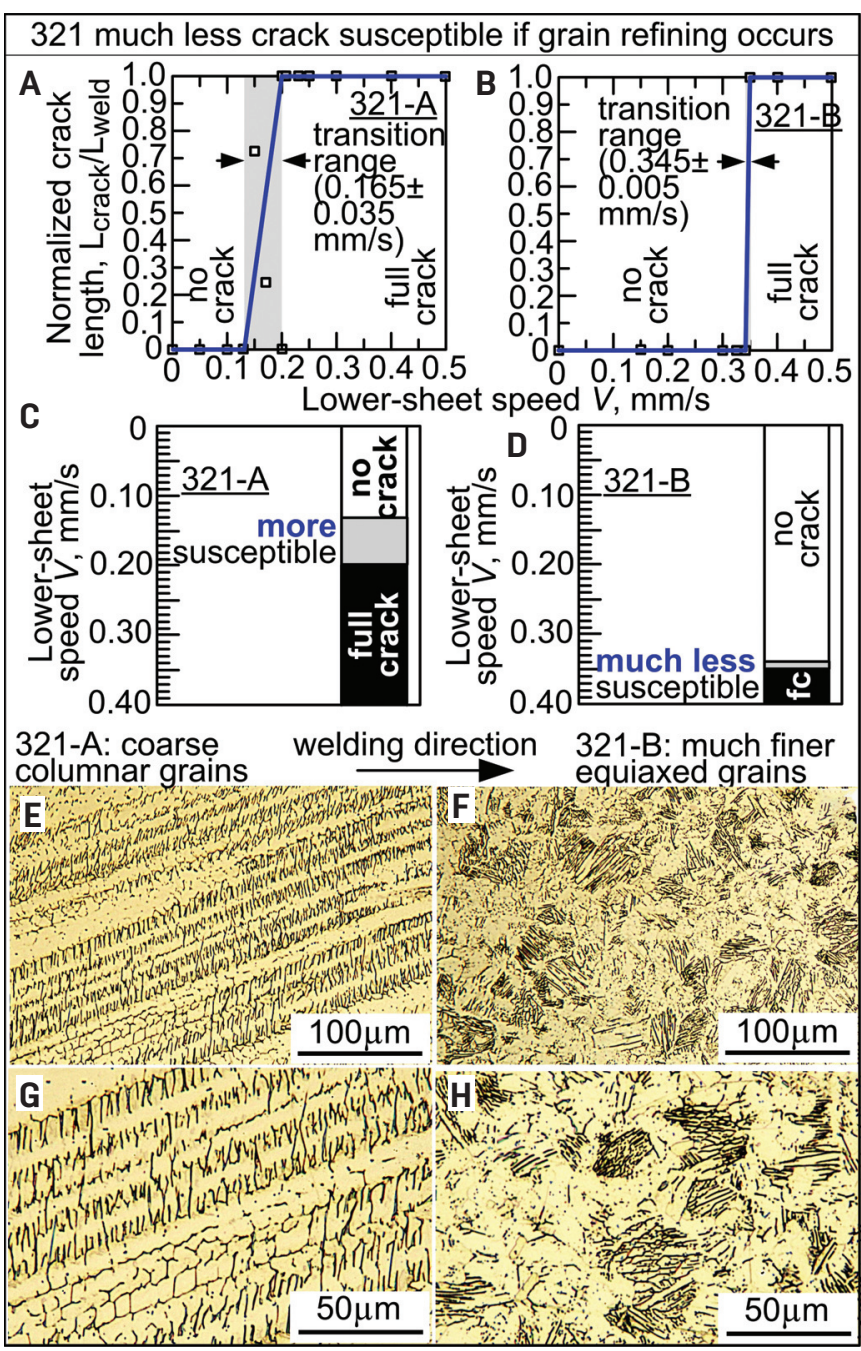

Fig. 10 - Comparison between the two heats of 321: $A, C, E$, G - 321-A; B, D, F, H-32l-B. A-D show the TMW test results and crack susceptibility. $E-H$ show the longitudinal vertical optical micrographs near the centerlines of the welds.

fusion zone, which may not exist at elevated temperatures during welding.

Figure 15 shows the results of 304L quenched during welding. The liquid along the boundaries between $\delta$-dendrites appeared discontinuous and isolated. The liquid was likely depleted by both fast back diffusion into bcc ( $\delta$-dendrites) and significant $L+\delta+\gamma$ reaction, which consumed $\mathrm{L}$ while forming $\gamma$. This is further explained as follows.

Figure 15A illustrates the vertical section of the $\mathrm{Fe}-\mathrm{Cr}-\mathrm{Ni}$ phase diagram at 74 wt- $\%$ Fe (Ref. 30), showing the solidification of $\mathrm{Fe}-18 \mathrm{Cr}-8 \mathrm{Ni}$, which is essentially 304 . The optical micrograph in Fig. 15B was taken near the centerline of the top surface of the mushy zone. Most of the weld pool had been pushed out by liquid Wood's metal during quenching, but a small amount of the quenched weld pool can still be seen near the pool boundary, i.e., the front of the mushy zone. Columnar dendrites growing in the welding direction are visible.

In view of Fig. 15A, 304 ( Fe-18Cr-8Ni) can be expected to solidify as primary $\delta$-ferrite under the normal cooling

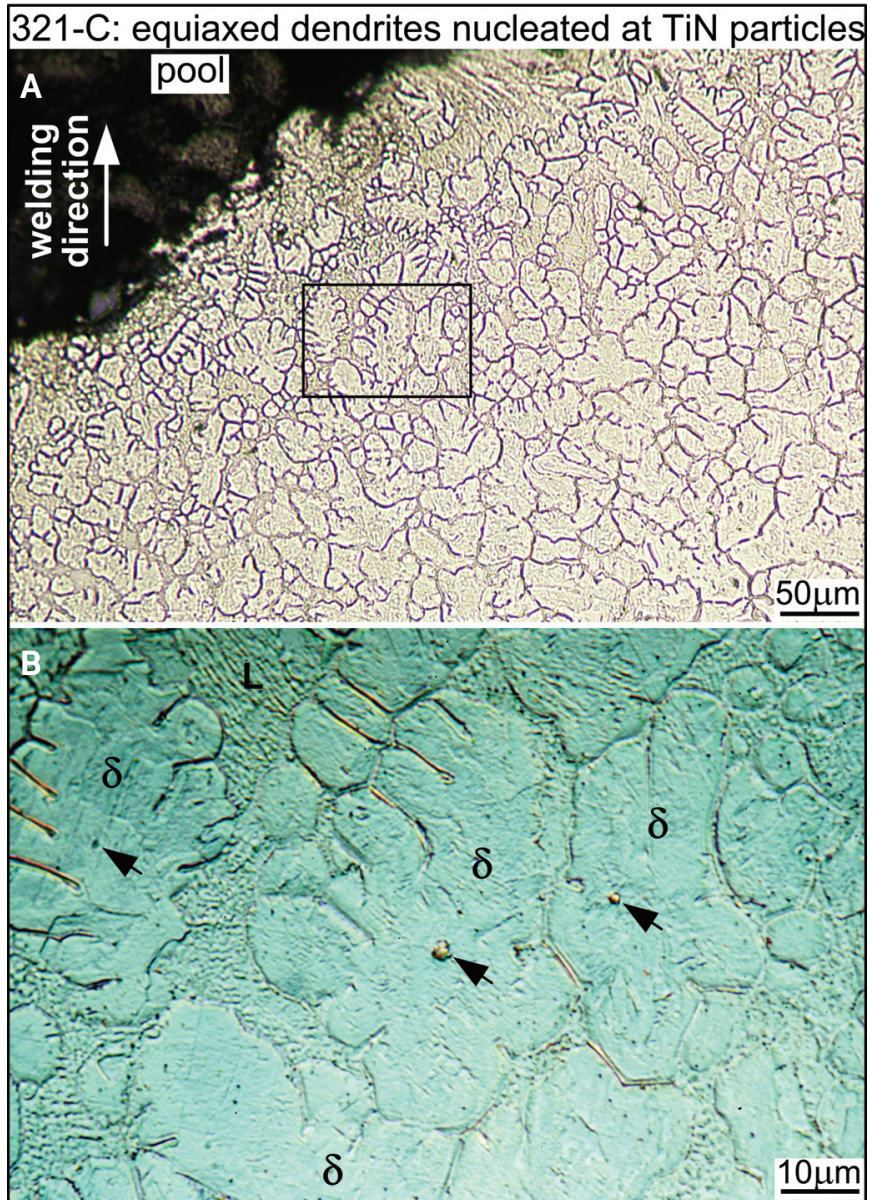

Fig. 11 - Equiaxed dendritic solidification mode of 321-C: A Longitudinal horizontal optical micrograph at the top surface of the mushy zone near its centerline behind the weld pool; $B-$ boxed area in A enlarged and photographed with DIC. Arrows indicate likely heterogenous nucleation sites.

rate encountered in arc welding. That is, the columnar dendrites in Fig. 15B are $\delta$-ferrite. This is confirmed by the EBSD phase map in Fig. 15C, which shows the dendrites as bcc and the interdendritic regions as fcc. In the previous study from Yu et al. (Ref. 17), EBSD was also used for phase identification. However, the location of EBSD analysis was well behind the pool boundary and near the end of the mushy zone, where the secondary dendrite arms were no longer clear to help distinguish dendrites from interdendritic regions. Consequently, the EBSD only revealed alternating bands of $\delta$ and $\gamma$. Thus, Fig. 15C provides further confirmation of the primary $\delta$-dendrites in the mushy zone of $304 \mathrm{~L}$.

As can be seen in Fig. 15B, the secondary arms of the $\delta$ dendrites were clear near the pool boundary but vague just slightly behind it. That is, the secondary dendrite arms coarsened very quickly during solidification. This was a clear indication of fast diffusion in $\delta$-ferrite, which was consistent with its bcc structure. Diffusion is much faster in a bcc solid such as $\delta$-ferrite than in a fcc solid such as austenite $\gamma$ (Refs. 31, 32). Back diffusion can be expected to be much faster in $\delta$-dendrites than in $\gamma$-dendrites. Fast back diffusion causes the interdendritic liquid to diminish quickly during solidification (Ref. 23). This has been 
shown in Al alloys (Refs. 33-36), which leads to discontinuous dendrite-boundary liquid and hence early bonding of Al-rich dendrites to each other to better resist solidification cracking (Refs. 37, 38).

Figure 15D shows the SEM images of the upper boxed area in Fig. 15B. The boundary between two columnar $\delta$ dendrites is visible. The smooth phase that exists continuously along the dendrite boundary is the $\gamma$ that has formed by the $L+\delta+\gamma$ three-phase reaction during solidification. As can be seen in the vertical section for 304 in Fig. 15A, the apex of the $L+\delta+\gamma$ three-phase triangle was only slightly below the liquidus temperature of 304. Thus, the threephase reaction may occur shortly after solidification starts, i.e., shortly behind the pool boundary. The liquid that still existed in the mushy zone was quenched. During electroetching, the quenched residual liquid $\mathrm{L}$ dissolved in the etching solution and left behind holes and grooves. A similar microstructure is shown in Fig. 15E, which is the SEM image of the lower boxed area in Fig. 15B. In the SEM image of a 304 stainless steel quenched during directional solidification and electroetched with oxalic acid, $\gamma$ also appeared smooth and the quenched residual liquid was also etched out as holes or grooves (Refs. 39-41).

It is worth pausing here to point out that, in austenitic stainless steels, an $L+\delta+\gamma$ reaction may occur by the peritectic reaction $\mathrm{L}+\delta \rightarrow \gamma$, which consumes both $\mathrm{L}$ and $\delta$ to form $\gamma$. The reaction may also occur by the eutectic reaction $\mathrm{L} \rightarrow \delta+\gamma$, which consumes $\mathrm{L}$ to form both $\delta$ and $\gamma$. It seems that a clear composite-like eutectic of $\delta+\gamma$ has not been reported. In fact, it is still unclear now which reaction occurs in 304 stainless steel.

Thus, the liquid along the boundaries between $\delta$-dendrites was depleted to become discontinuous and isolated by both fast back diffusion into bcc (dendrites of $\delta$ ) and significant $\mathrm{L}+\delta+\gamma$ reaction, which consumed $\mathrm{L}$ while forming $\gamma$ along the boundaries. This explained the low susceptibility of 304L. The recent study of Yu et al. (Ref. 17) was the first to attribute the low susceptibility of 304 to the $L+\delta+\gamma$ reaction.

According to Fig. 15A, the $\delta \rightarrow \gamma$ solid-state transformation can occur when the $\delta+\gamma$ two-phase region is reached during cooling. In Fig. 15B, the broken horizontal line indicates the onset of the $\delta \rightarrow \gamma$ transformation. The amount of $\delta$ decreased with increasing distance behind the line. Far behind this line, as shown in Fig. 15F, only thin residual $\delta$ was left in the $\gamma$-matrix of the fusion zone. Lacy $\delta$-ferrite can be seen on the left half and skeletal $\delta$-ferrite in the right half.

Thus, it is clear that the lacy/skeletal $\delta$ structure cannot resist solidification cracking as widely believed because it does not even exist in the mushy zone, where solidification cracking occurs. It exists in the fusion zone far behind the mushy zone.

It is worth mentioning that, for austenitic stainless steels, the calculated freezing temperature range may not necessarily correlate well with the crack susceptibility. When back diffusion is significant, the calculated freezing temperature range may be too wide if the Scheil solidification model (Ref. 23) is used because the model does not consider back diffusion. To consider back diffusion, a kinetics model is also needed, and the shape of dendrites needs to be assumed as an approximation (e.g., planar, cylindrical, or spherical). The diffusion coefficients may not be readily available for multicomponent alloys, such as austenitic stainless steels. The

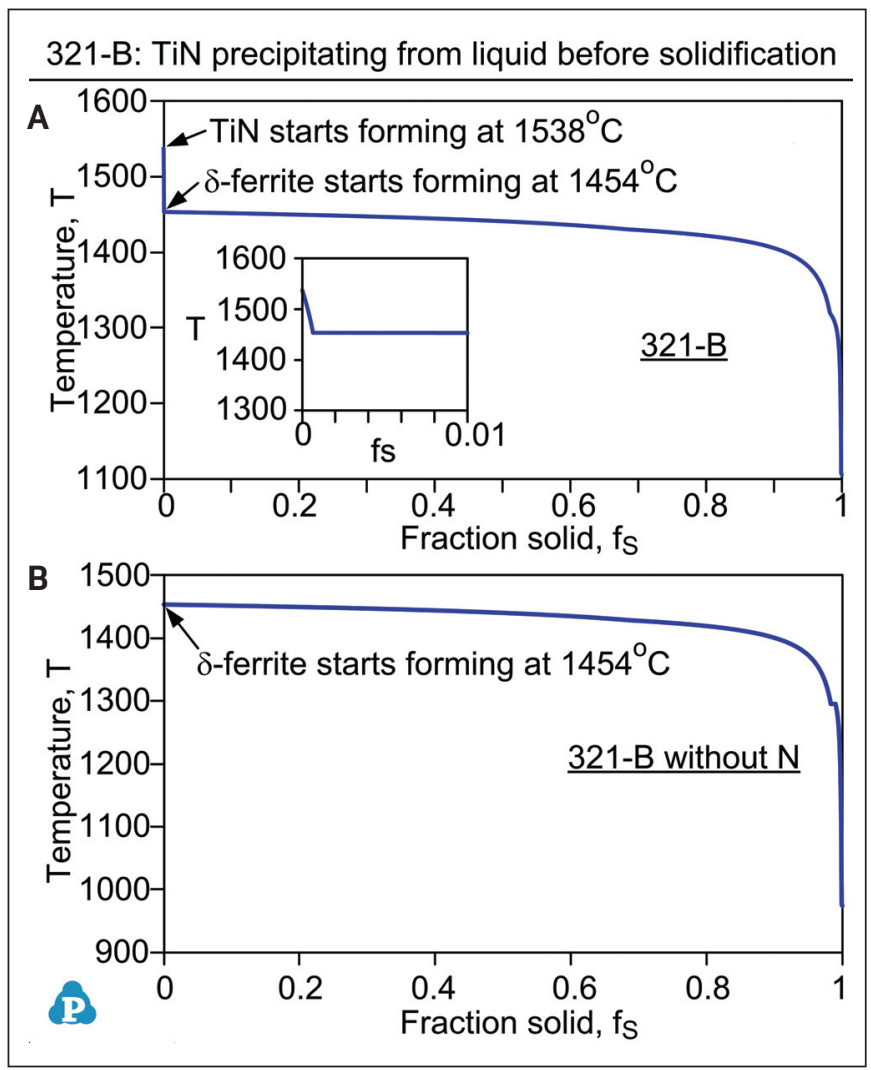

Fig. 12 - Solidification paths of 321-B: A - With the exact composition of 321-B used (including 0.016 wt-\% $N$ and 0.2 wt-\% Ti) and showing precipitation of TiN from the liquid before solidification starts; $B$ - with the same composition except with no $\mathrm{N}$ and showing no precipitation.

freezing temperature range during welding can also be difficult to measure accurately.

\section{L Microstructure and Crack Resistance}

Figure 16 is the microstructure of $316 \mathrm{~L}$ quenched during welding, shown near the centerline of the top surface of the mushy zone. Figure 16A shows an optical micrograph taken with DIC. According to the phase diagram, calculated based on the composition of 316L shown in Table 1 using the thermodynamics software Pandat (Ref. 26) and the database PanFe (Ref. 27), 316L should solidify as primary $\delta$-ferrite. Thus, $\delta$-dendrites can be expected to grow in the mushy zone.

Figure $16 B$ and $C$ is, respectively, the SEM images of the upper and lower boxed areas in Fig. 16A. Figure 16C is located at the boundary between two columnar grains growing in two different directions, where much liquid was trapped when one grain impinged upon the other at an angle during solidification. As mentioned previously, the smooth phase that existed continuously along the dendrite boundary was the $\gamma$ that formed by the $L+\delta+\gamma$ reaction during solidification. The holes and grooves were left by the quenched residual liquid that dissolved in the etching solution during electro etching. Thus, as in the case of 304L (Fig. 15), the low crack susceptibility of 316L can be attributed to the depletion of the dendrite-boundary liquid by fast back diffusion 


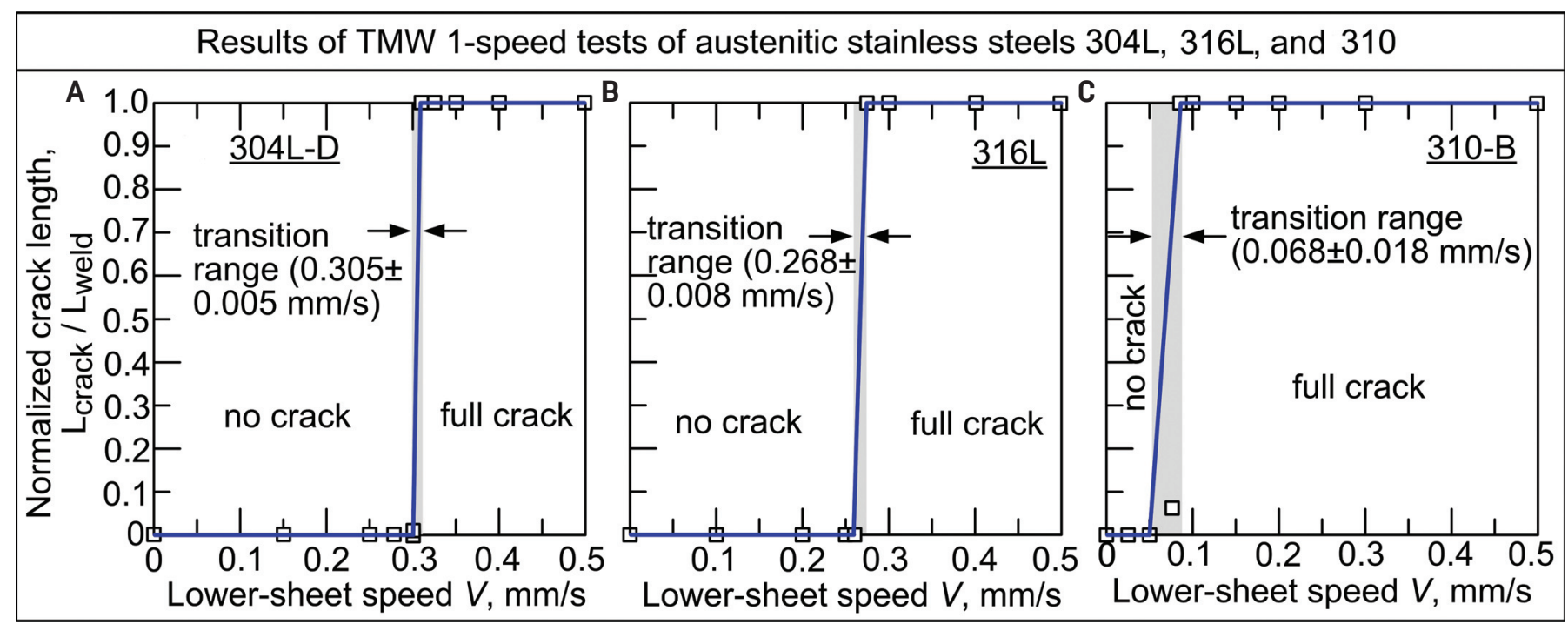

Fig. 13 - Results of the TMW one-speed tests of austenitic stainless steels: A - 304L; B - 316L; C - 310.

into $\delta$-dendrites (bcc) and the $\mathrm{L}+\delta+\gamma$ reaction that consumed L while forming $\gamma$.

As in 304L, lacy or skeletal $\delta$ formed not in the mushy zone but in the fusion zone far behind it, as shown in Fig. 16D. This, again, indicates that the lacy/skeletal $\delta$ structure cannot resist solidification cracking as was widely believed.

\section{Microstructure and Crack Resistance}

Figure 17A is the vertical section of the $\mathrm{Fe}-\mathrm{Cr}$-Ni phase diagram at 55 wt-\% Fe (Ref. 42). It shows Fe-25Cr-20Ni, which is close to 310 , should solidify as primary austenite $\gamma$. Figure 17B displays the microstructure of quenched 310. Columnar $\gamma$-dendrites grew in the mushy zone. As shown, 310 ( Fe-25Cr-20Ni) should solidify as primary $\gamma$. This has been confirmed by EBSD (Ref. 17). As displayed in Fig. 17C, deep into the mushy zone, the $\gamma$-dendrites were still separated by continuous liquid films. The $L+\delta+\gamma$ reaction formed particles of $\delta$, as can be seen in Fig. 17D. However, overall, the $\mathrm{L}+\delta+\gamma$ reaction did not significantly form $\delta$ in 310 and did not significantly consume liquid. As mentioned previously, back diffusion is much slower in fcc solids than in bcc solids. Thus, the liquid along the boundaries of $\gamma$-dendrites was not significantly depleted either by back diffusion nor by the $L+\delta+\gamma$ reaction. Consequently, columnar $\gamma$-dendrites were separated from each by continuous liquid films and could thus be easily pulled apart under tension to cause solidification cracking.

The long, straight boundaries between $\gamma$-dendrites can be another problem for 310. As can be seen in Fig. 17B, the $\gamma$ dendrites often have thick primary arms with relatively short secondary arms. In fact, the macrographs of 310 welds show coarse, straight grains in the fusion zone (Ref. 17). On a long, straight boundary between $\gamma$-dendrites, even a very small amount of liquid may be enough to form a continuous film, as shown in Fig. 17C. A long, straight boundary is also an easy path for crack initiation and propagation. To sum up, 310 resists cracking poorly because thin continuous liquid films persist along $\gamma$-dendrite boundaries due to the following: 1) slow back diffusion in $\mathrm{fcc}(\gamma) ; 2)$ insignificant $\mathrm{L}+\delta+\gamma$ reaction; and 3) long, straight $\gamma$-dendrite boundaries.

\section{Sulfur Increases Crack Susceptibility}

To show that the TMW test can correctly determine the effect of sulfur on solidification cracking, additional TMW testing was conducted using 304L-B as the lower sheet, which contained 0.003 wt-\% S, and 304L-A as the upper sheet, which contained significantly more $S$, i.e., 0.014 wt-\% S. The transverse cross section of the lap weld showed it consisted of $37 \%$ of the upper sheet and $63 \%$ of the lower sheet. Assuming good mixing in the weld pool, the weld S content $(\mathrm{S} \%)_{\text {weld }}=0.37$ $(0.014 \%)+0.63(0.003 \%)=0.007 \%$. The results of the onespeed TMW test are shown in Fig. 18, with those of 304L-D (Fig. 13A) included for comparison. As shown, the crack susceptibility at $0.007 \mathrm{wt}-\% \mathrm{~S}$ was higher than that at $0.003 \mathrm{wt}-\%$ $\mathrm{S}$. This is consistent with the well-known fact that $\mathrm{S}$ increases the susceptibility of stainless steels to solidification cracking (Refs. 1, 2).

\section{Slower Welding Speed Increases Crack Susceptibility}

To determine the effect of the welding speed (torch travel speed) on solidification cracking, 304L-C was welded at $0.635 \mathrm{~mm} / \mathrm{s}$ in the two-speed TMW test and compared to that welded at $1.27 \mathrm{~mm} / \mathrm{s}$. As shown in Fig. 19, the crack susceptibility was higher at the lower welding speed. When the welding speed was reduced under the same welding current and voltage, the mushy zone became larger, thus widening the region vulnerable to solidification cracking.

\section{Accuracy of Test Results}

The transition range is shown as the average \pm error in Figs. $6,7,10,13,18$, and 19 . The average was taken as the centerline of the range, and the error was taken as the half 
Crack susceptibility of austenitic stainless steels ranked by TMW test and other tests

A Susceptibility to crack initiation by 1-speed test
B Susceptibility to crack propagation by 2 -speed test c Varestraint test
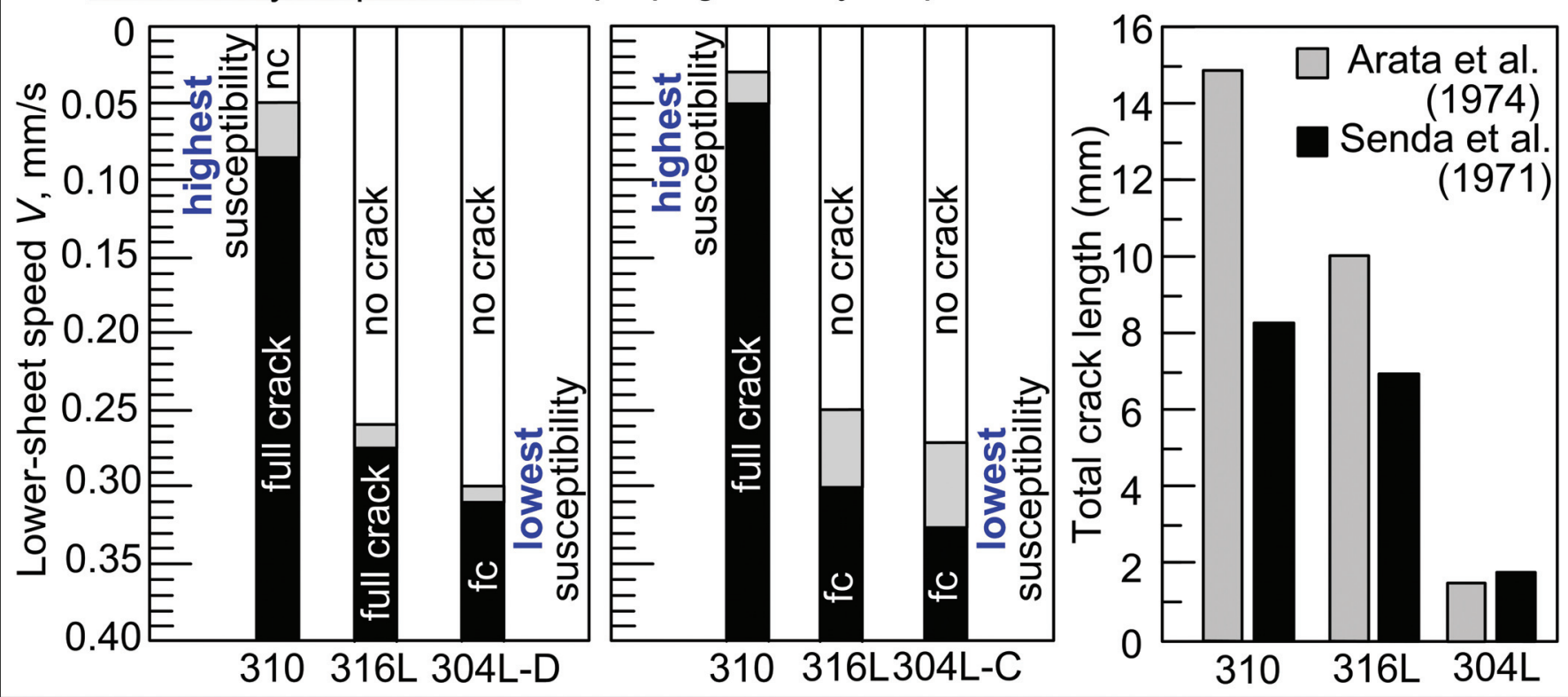

Fig. 14 - Crack susceptibility ranking of $310>316 \mathrm{~L}>304 \mathrm{~L}: \mathrm{A}-$ Based on the one-speed test (Fig. 13); B - based on the two-speed test (Fig. 6); $C$ - based on the Varestraint test. In $A$ and $B$, the higher the transition range of $V$ needed to cause full cracking, the lower the susceptibility. Susceptibility ranking in A and B is consistent with that in $C$.

width of the range. Below the range, the normalized crack length was always zero. Above the range, it was always 1.0. The accuracy or repeatability of the test results is further discussed as follows.

First, in each of the 12 different cases tested, a distinct transition range was observed. Second, an average of ten welds were made in each case to determine the transition range. The error in the location of the transition range was mostly from \pm 0.005 to $\pm 0.030 \mathrm{~mm} / \mathrm{s}$. In three cases, the error was larger at $\pm 0.050 \mathrm{~mm} / \mathrm{s}$. The first case involved ferritic stainless steel 430 (Fig. 7A), which is known for its severe grain growth in the HAZ. The coarse HAZ grains could affect the fusion-zone grain structure significantly, and this effect might vary from weld to weld, thus widening the error.

The second case was duplex stainless steel 2205 (Fig. 7B). The amount of austenite and ferrite relative to each other and their distributions might vary somewhat from workpiece to workpiece, thus widening the error. The last case involved welding two sheets of different S contents (Fig. 18B). The relative amounts of the upper sheet $(0.014 \mathrm{wt}-\% \mathrm{~S})$ and the lower sheet $(0.003 \mathrm{wt}-\% \mathrm{~S})$ in the weld might vary somewhat from weld to weld, thus causing more error. In any case, making more than ten welds may change the width of the transition range somewhat, but the location (the centerline of the width) of the transition range on the $V$-axis should change less. Since the crack susceptibility is determined by the location of the transition range, not the width, the test results are expected to be accurate. The accuracy of the test results has also been shown by their consistency with the data from Lippold and Kotecki (Ref. 1), Arata et al.
(Ref. 28), and Senda et al. (Ref. 29).

When the welding conditions and the sample size are changed, the test results are expected to be affected. However, if reasonable changes are made to all stainless steels being tested, the resultant relative crack susceptibility should be similar. This is true with other test methods as well, such as Varestraint testing.

\section{Strain Rates}

It has been recognized that the strain rate plays an important role in solidification cracking (Refs. 37, 38, 43). It is obvious that a significant amount of strain may not necessarily cause solidification cracking if it is applied so slowly that solidification already ends while the strain is still increasing.

In the Varestraint test, the global strain and the strain rate in the workpiece can be very different from the local strain and strain rate in the mushy zone, where solidification cracking occurs (Refs. 44, 45). Coniglio (Ref. 44) pointed out that, in Varestraint testing, the weld metal shows significantly higher strains (more than 2\%) and strain rates (more than 100\%/s) than the applied strain (0.5\%), and the strain rate $(40 \% / \mathrm{s})$ on the workpiece surface was calculated based on $\varepsilon=H /(2 R+H)$ $\times 100 \%$. $\varepsilon$ is strain, $H$ is workpiece thickness, and $R$ is the radius of the bending block. So, in the Varestaint test, the selfinduced strain is not necessarily minimized so that the externally applied strain alone can be used as the crack-susceptibility index. This seems to be also true with other tests. Bakir et al. (Ref. 46) showed in the controlled tensile weldability test of 304 stainless steel by laser beam welding that the local strain 


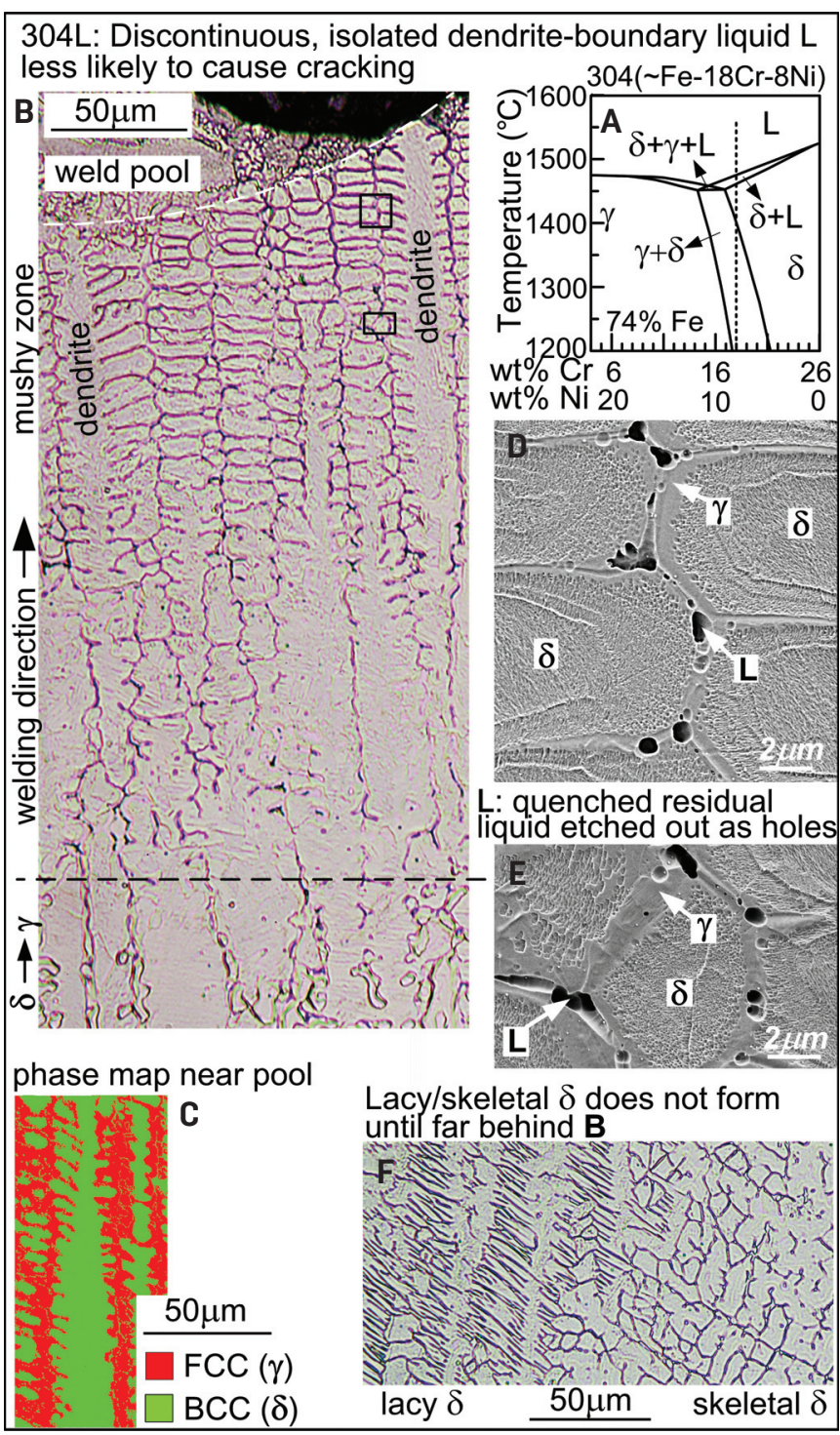

Fig. $15-304 \mathrm{~L}$ quenched during welding: A - Vertical section of the $\mathrm{Fe}-\mathrm{Cr}$-Ni phase diagram showing $\mathrm{Fe}-18 \mathrm{Cr}-8 \mathrm{Ni}$ (close to 304) solidifies as primary ferrite $\delta$ (Ref. 32); B - microstructure near the centerline of the weld top surface behind the weld pool; $C$ - phase map showing bcc dendrites and fcc interdendritic regions; $D$ - SEM image of upper boxed area in $B ; E-$ lower boxed area in B; F-lacy/skeletal $\delta$ far behind $B$.

rate near the crack (e.g., 18\%/s) can be much higher than the global strain rate (e.g., 4\%/s). In the TMW test of $6061 \mathrm{Al}$ by GTAW, the local strain rate near the crack (e.g., 8\%/s) can also be higher than the global strain rate across the top width of the weld (e.g., $0.7 \% / s$ nominal, i.e., without including the curvature effect of the weld top surface) (Ref. 47).

\section{Effect of Quenching}

Liquid-metal quenching during welding has been used to study solidification and phase transformations in stainless steel welds (Refs. 7, 25, 48-51) since Kou and Le (Ref. 48) first demonstrated liquid-Sn quenching. Liu et al. (Ref. 36) used liquid Wood's metal to quench $\mathrm{Al}$ alloys during welding. Yu et al. (Ref. 17) used liquid Wood's metal to quench stain-

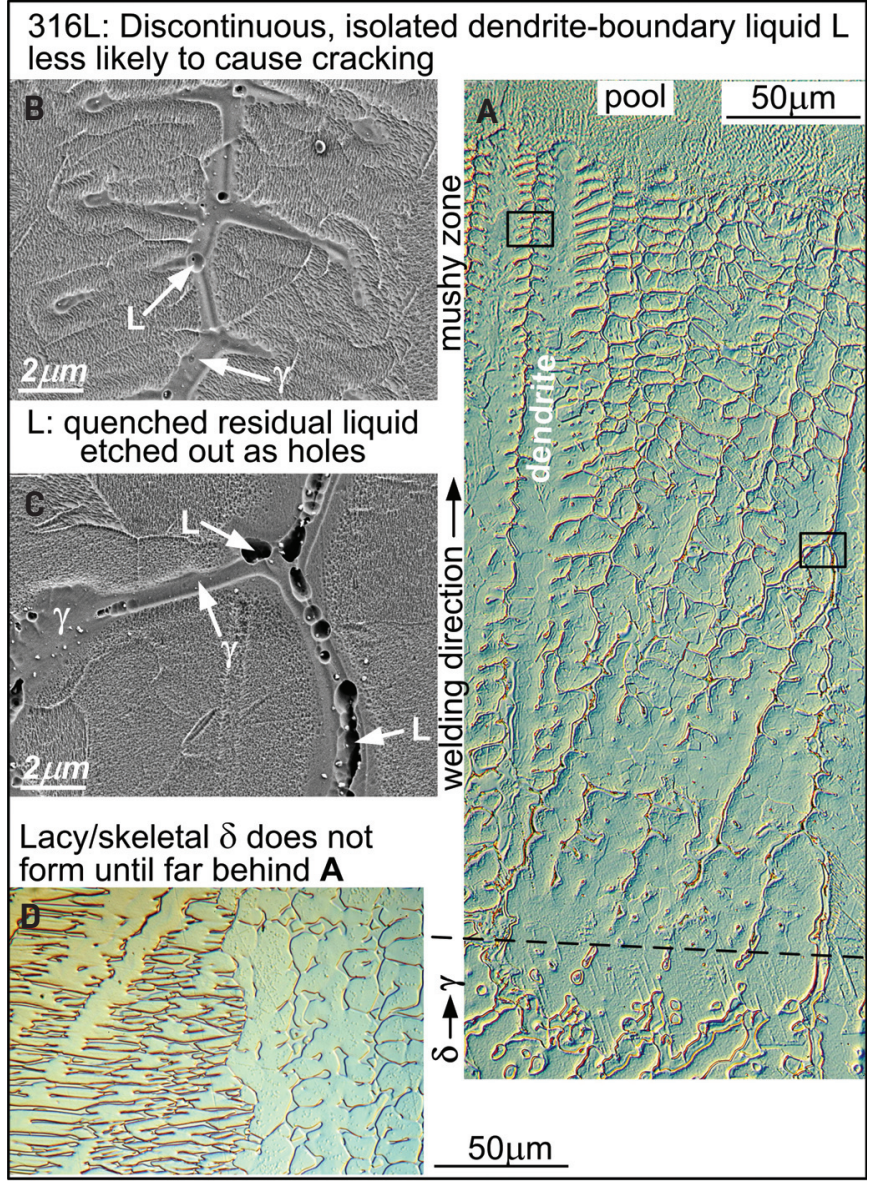

Fig. 16 - Microstructure near the centerline of the top surface of the 316L weld quenched during welding: A - Behind the weld pool (DIC); B - SEM image of the upper boxed area in $A ; C$ - lower boxed area in $A ; D$ - lacy/skeletal $\delta$ far behind $A(D I C)$.

less steels during welding.

Before quenching is applied during welding, phase transformations and changes in phase fractions in the $L+\delta$ and $\delta+\gamma$ regions have already occurred under normal welding without quenching. The extents of the transformations increase with increasing distance behind the pool boundary. Far behind the pool boundary, transformations are nearly complete. These extents can be "frozen-in" or "captured" by quenching because rapid cooling allows hardly any time for diffusion to change them any further. Thus, the fractions of $\delta$, $\gamma$, and L during normal solidification can be "frozen-in" by quenching. This is why quenching is used both in directional solidification (Refs. 39-41) and welding (Refs. 7, 17, 25, 48-51).

Brooks et al. (Ref. 51) quenched stainless steel with liquid Sn during welding. Microsegregation in the transverse direction across the dendrites was clearer near the pool boundary and gradually faded away from the pool boundary. Liu et al. (Ref. 36) quenched $2014 \mathrm{Al}(\sim \mathrm{Al}-4.4 \mathrm{Cu})$ and $5086 \mathrm{Al}(\sim \mathrm{Al}-$ $4 \mathrm{Mg}$ ) with liquid Wood's metal during welding. In both cases, the dendrite arms were finer, and microsegregation was clearer near the pool boundary and gradually coarsened and faded, respectively, away from the pool boundary. These are examples showing the use of quenching to "freeze-in" the evolution 


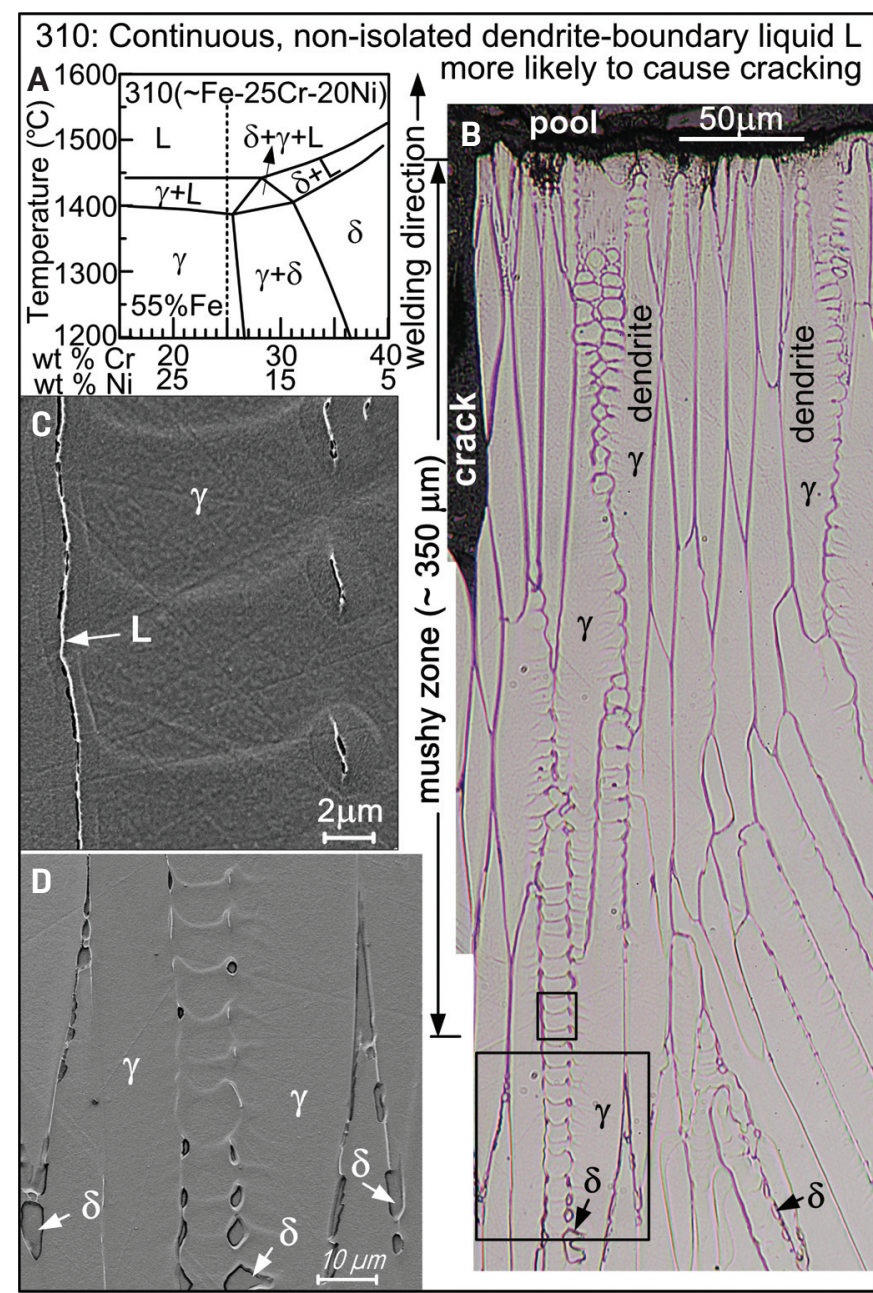

Fig. $17-310$ quenched during welding: $A-$ Vertical section of the Fe-Cr-Ni phase diagram showing Fe-25Cr-20Ni (close to 310) solidifies as primary austenite $\gamma$ (Ref. 42); B-microstructure near the centerline of the weld top surface behind the weld pool; $C$ - SEM image of the small boxed area in B; $D-$ big boxed area in $B$. Wide mushy zone $(\sim 350 \mu \mathrm{m})$ and coarse grains further reduce crack resistance.

of microstructure and microsegregation in normal welding.

With primary- $\gamma$ solidification such as in 310 , the interdendritic liquid solidifies into $\gamma$ as expected. With primary- $\delta$ solidification such as in 304L, however, the interdendritic liquid solidifies into the metastable phase $\gamma$ (fcc) instead of the equilibrium phase $\delta$ (bcc). This has been confirmed by EBSD and is caused by fast cooling during quenching. This is consistent with the well-known primary- $\gamma$ solidification of 304 in laser beam welding, where the cooling rate is very high.

At the pool boundary, as shown in Fig. 20, the solidification structure of the interdendritic liquid was fine cells of $\gamma$ for 310 as well as 304L. The fine cellular solidification structure was caused by the fast cooling rate during solidification. For 304L, the $\gamma$ cells between the dendrites were confirmed by EBSD.

Inside the $304 \mathrm{~L}$ mushy zone, the $\delta$-dendrites remained as dendrites during quenching. Perhaps after the mushy zone was solidified completely and continued to cool during quenching, some $\delta$-dendrites might transform into $\gamma$. It is still being investigated if massive transformation could oc-

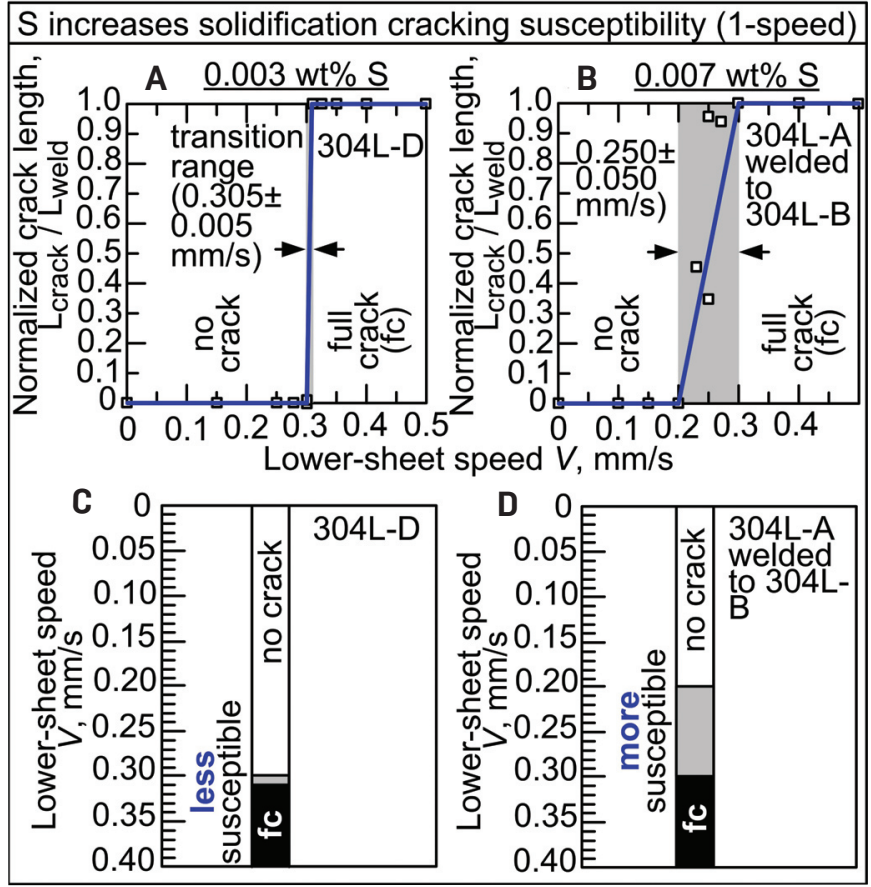

Fig. 18 - Effect of sulfur content on solidification cracking susceptibility shown by the one-speed TMW test: $A, C-$ 304L-D with 0.003 wt-\% S; B, D - 304L-A (0.014 wt-\% S) welded to $304 \mathrm{~L}-\mathrm{B}(0.003 \mathrm{wt}-\% \mathrm{~S})$.

cur under fast cooling during quenching. Since this is a solid-state transformation that takes place after solidification ends, it cannot affect solidification cracking. Thus, the nonequilibrium kinetics caused by quenching-induced fast cooling, whether it is the rapid solidification of the interdendritic liquid in the mushy zone into the metastable phase $\gamma$ or the possible massive transformation of some $\delta$-dendrites in the mushy zone into $\gamma$, do not affect the discussion on the crack susceptibility.

\section{Summary and Conclusions}

The new TMW test, which has several significant advantages over the most widely used Varestraint test, was utilized to evaluate the susceptibility of stainless steels to solidification cracking. Although this study focused on austenitic grades, ferritic and duplex grades were also tested. The susceptibility differences among the tested austenitic grades were analyzed with the help of quenching during welding. Spontaneous grain refining was found to occur in some welds and greatly reduced their susceptibility. Furthermore, a new explanation for the susceptibility was proposed based on the continuity of the liquid along the boundaries between columnar dendrites and the reduction of the continuity due to the depletion of the liquid caused by fast back diffusion and significant $\mathrm{L}+\delta+\gamma$ reaction. The TMW test further demonstrated the significant effect of the sulfur content and the welding speed on the susceptibility. The present study represents a significant extension beyond the recent study by Yu et al. (Ref. 17) on 304 and 310 without susceptibility testing. Their new explanation for the much lower susceptibility of 304 


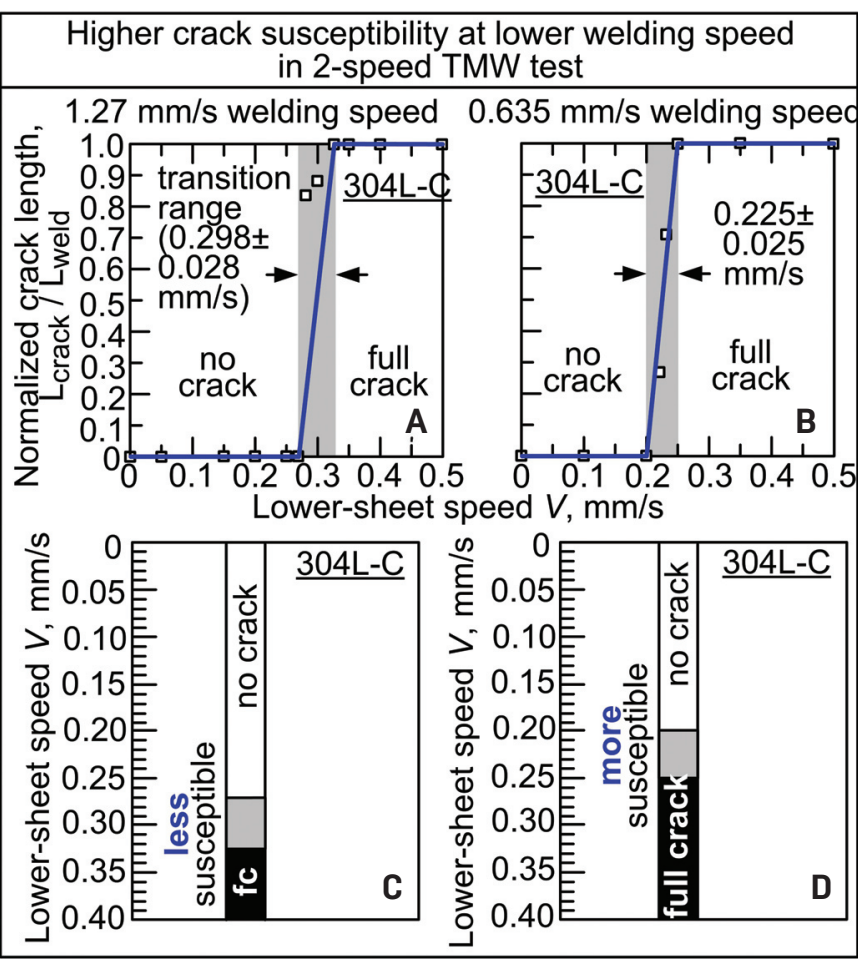

Fig. 19 - Effect of welding speed on solidification cracking susceptibility shown by the two-speed TMW test: $A, C-1.27$ $\mathrm{mm} / \mathrm{s} ; \mathrm{B}, \mathrm{D}-0.635 \mathrm{~mm} / \mathrm{s}$.

than 310 was based on the $L+\delta+\gamma$ reaction, which is included as part of the new explanation in the present study.

The conclusions of the present study are as follows:

1) The new TMW test was used to evaluate the susceptibility of stainless steels to solidification cracking, including austenitic, ferritic, and duplex stainless steels. The relative crack susceptibility of 304L, 310, 316L, 430, and 2205 was consistent with the Varestraint test data.

2) The TMW test can evaluate the crack susceptibility based on either crack initiation or crack propagation, as demonstrated using 304L, 310, and 316L. Both tests showed that the susceptibility decreased in the order of $310>316 \mathrm{~L}>304 \mathrm{~L}$.

3) The TMW test showed the susceptibility of 321 can vary significantly, from being significantly more susceptible than 304L to less. The low-susceptibility 321 welds were found to have very fine equiaxed grains in the fusion zone, which are known to help resist solidification cracking. Quenching 321 during welding confirmed that fine equiaxed grains formed in the mushy zone, most likely by heterogeneous nucleation on TiN particles, as shown by thermodynamic calculations. Thus, grain refining by TiN may occur in 321 with sufficient $\mathrm{Ti}$ and $\mathrm{N}$ and under favorable welding conditions.

4) A new explanation for crack susceptibility has been proposed. The susceptibility is high if the liquid along the boundaries between columnar dendrites is continuous because the dendrites can be easily separated under tension. However, it could be much lower if the liquid is depleted by fast back diffusion and a significant $L+\delta+\gamma$ reaction, making the liquid discontinuous and isolated and allowing the dendrites to bond to each other early to resist cracking wherever the liquid is absent.

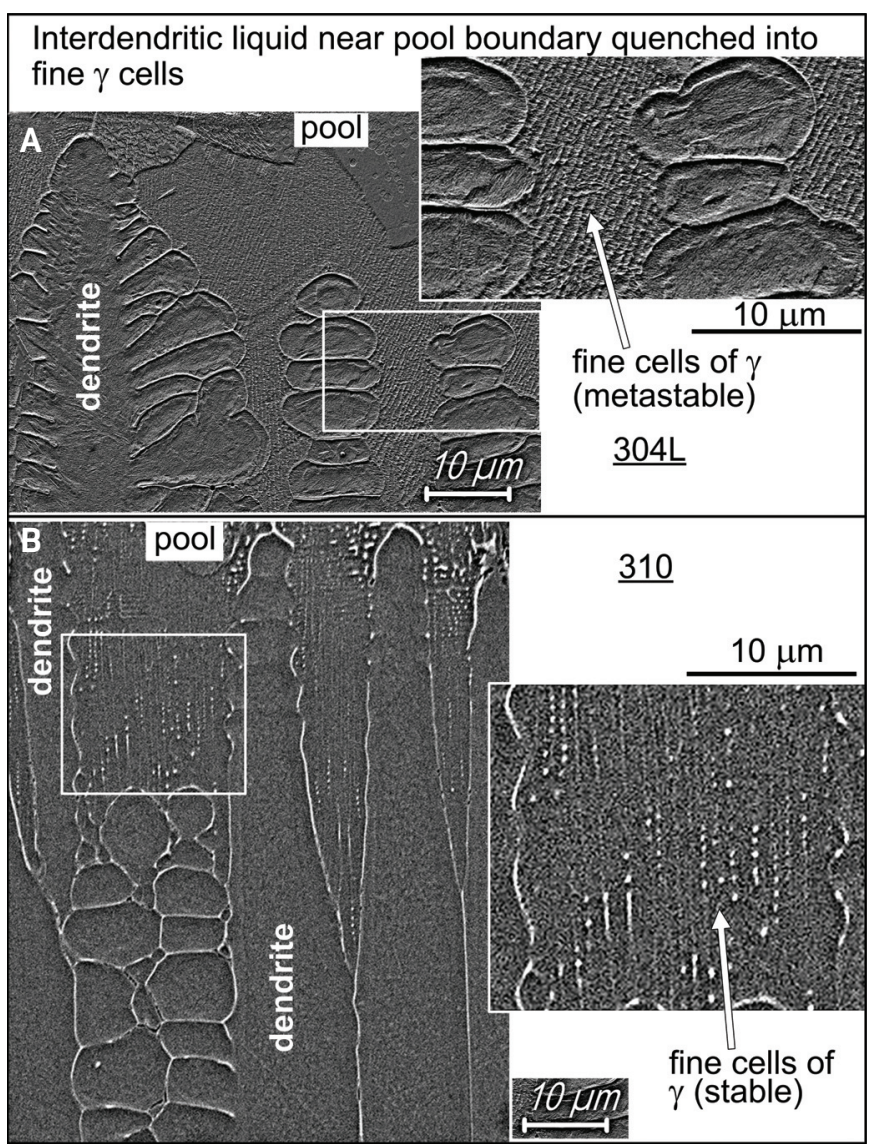

Fig. 20 - Rapid solidification of the interdendritic liquid near dendrite tips into very fine cells of $\gamma$ : $A-304 L ; B-310$. Boxed areas are enlarged. $\gamma(f c c)$ is confirmed by EBSD.

5) In 304L and 316L, the liquid between $\delta$-dendrites was discontinuous and isolated as revealed by quenching. Back diffusion was fast in bcc ( $\delta$-dendrites), and the $L+\delta+\gamma$ reaction consumed $\mathrm{L}$ while forming $\gamma$. In 310, however, the liquid between $\gamma$-dendrites was continuous. Back diffusion was much slower in fcc ( $\gamma$-dendrites) than bcc, and the $L+\delta+\gamma$ reaction formed little $\delta$.

6) The much lower susceptibility of 304L and 316L than 310 shown by the TMW test cannot be explained based on the fusion-zone microstructure of lacy/skeletal $\delta$ in a $\gamma$ matrix. As revealed by quenching, this microstructure forms far behind the mushy zones of 304L and 316L, well after solidification ends. Thus, the lacy/skeletal $\delta$ structure is unlikely to resist solidification cracking, as was widely believed for decades.

7) Increasing the $S$ content and decreasing the welding speed both tend to increase the solidification cracking susceptibility, as demonstrated by further TMW testing on 304L.

\section{Acknowledgments}

This work was supported by the National Science Foundation under Grant No. DMR1904503. Kun Liu was a visiting graduate student at the University of Wisconsin-Madison, supported by the China Scholarship Council under Grant No. 201706220201. The author, Sindo Kou, would like to thank 
Toshihiko Koseki, Department of Materials Engineering, The University of Tokyo, Japan, for helpful discussions.

\section{References}

1. Lippold, J. C., and Kotecki, D. J. 2005. Welding Metallurgy and Weldability of Stainless Steels. Hoboken, N.J.: John Wiley and Sons.

2. Kou, S. 2020. Welding Metallurgy, $3^{\text {rd }}$ ed. Hoboken, N.J.: John Wiley and Sons.

3. Shankar, V., Gill, T. P. S., Mannan, S. L., and Sundaresan, S. 2003. Solidification cracking in austenitic stainless steel welds. Sadhana 28(3-4): 359-382. DOI: 10.1007/BF02706438

4. Masumoto, I., Tamaki, K., and Kutsuna, M. 1972. Hot cracking of austenitic stainless steel weld metal. Transactions of Japan Welding Society 41(11): 1306-1314. DOI: 10.2207/qjjws1943.41.1306

5. David, S. A., Goodwin, G. M., and Braski, D. N. 1979. Solidification behavior of austenitic stainless steel filler metals. Welding Journal 58(11): 330-s to 336-s. DOI: 10.2172/5563513

6. Elmer, J. W., Allen, S. M., and Eagar, T. W. 1989. Microstructural development during solidification of stainless steel alloys. Metallurgical and Materials Transactions A 20(10): 2117-2131. DOI: 10.1007/BF02650298

7. Matsuda, F., Nakagawa, H., and Lee, J. 1987. Weld cracking in duplex stainless steel (Report I). Trans. of JWRI 16(2): 343-349.

8. Cross, C. E., Coniglio, N., Westin, E. M., and Gumenyuk, A. 2011. Laser weldability of stainless steel. Hot Cracking Phenomena in Welds III. Berlin: Springer-Verlag, pp. 131-144. DOI: 10.1007/ 978-3-642-16864-2-8

9. Tate, S. B., Javernick, D. A., Lienert, T. J., and Liu, S. 2016. Laser weldability of $21 \mathrm{Cr}-6 \mathrm{Ni}-9 \mathrm{Mn}$ stainless steel: Part I - Impurity effects and solidification mode. Welding Journal 95(10): 371-s to 383-s.

10. Borland, J. C., and Younger, R. N. 1960. Some aspects of cracking in welded $\mathrm{Cr}-\mathrm{Ni}$ austenitic steels. British Welding Journal 7(1): 22-59.

11. Matsuda, F., Nakagawa, H., Uehara, T., Katayama, S., and Arata, Y. 1979. A new explanation for role of delta-ferrite improving weld solidification crack susceptibility in austenitic stainless steel (materials, metallurgy, weldability). Transactions of JWRI 8(1): 105-112.

12. Hull, F. C. 1967. Effect of delta ferrite on the hot cracking of stainless steel. Welding Journal 46(9): 399-s to 409-s.

13. Pellini, W. S. 1952. Strain theory of hot tearing. Foundry 80(11): 125-133.

14. Brooks, J. A., Thompson, A. W., and Williams, J. C. 1984. A fundamental study of the beneficial effects of delta ferrite in reducing weld cracking. Welding Journal 63(3): 71-s to 83-s.

15. Kujanpaa, V. P. 1985. Effect of steel type and impurities in solidification cracking of austenitic stainless steel welds. Metal Construction 17(1): 40R-46R.

16. Thier, H., Killing, R., and Killing, U. 1987. Solidification modes of weldments in corrosion resistant steels - How to make them visible. Metal Construction 19: 127-130.

17. Yu, P., Thompson, K. J., McCarthy, J., and Kou, S. 2018. Microstructure evolution and solidification cracking in austenitic stainless steel welds. Welding Journal 97(11): 301-s to 314-s. DOI: 10.29391/2018.97.026

18. Soysal, T., and Kou, S. 2017. A simple test for solidification cracking susceptibility and filler metal effect. Welding Journal 96(10): 389-s to 401-s.

19. Soysal, T., and Kou, S. 2018. A simple test for assessing solidification cracking susceptibility and checking validity of susceptibility prediction. Acta Materialia 143: 181-197. DOI: 10.1016/ j.actamat.2017.09.065

20. Soysal, T., and Kou, S. 2019. Effect of filler metals on solidification cracking susceptibility of Al alloys 2024 and 6061. Journal of Materials Processing Technology 266: 421-428. DOI: 10.1016/ j.jmatprotec.2018.11.022
21. Savage, W. F., and Lundin, C. D. 1965. The Varestraint test. Welding Journal 44(10): 433-s to 442-s.

22. Kotecki, D. J., and Siewert, T. A. 1992. WRC-1992 constitution diagram for stainless steel weld metals: A modification of the WRC-1988 diagram. Welding Journal 71(5): 171-s to 178-s.

23. Flemings, M. C. 1972. Solidification Processing. New York, N.Y.: McGraw-Hill.

24. Villafuerte, J. C., Kerr, H. W., and David, S. A. 1995. Mechanisms of equiaxed grain formation in ferritic stainless steel gas tungsten arc welds. Materials Science and Engineering A 194(2): 187-191. DOI: 10.1016/0921-5093(94)09656-2

25. Koseki, T., Inoue, H., Fukuda, Y., and Nogami, A. 2003. Numerical simulation of equiaxed grain formation in weld solidification. Science and Technology of Advanced Materials 4(2): 183-195. DOI: 10.1016/S1468-6996(03)00026-3

26. Pandat ${ }^{\mathrm{TM}}$. 2019. Phase diagram calculation software package for multicomponent systems. CompuTherm LLC: Madison, Wis.

27. PanFe. 2019. Thermodynamic database for iron alloys. CompuTherm LLC: Madison, Wis.

28. Arata, Y., Matsuda, F., and Saruwatari, S. 1974. Varestraint test for solidification crack susceptibility in weld metal of austenitic stainless steels. Trans. of JWRI 3(1): 79-88.

29. Senda, T., Matsuda, F., Takano, G., Watanabe, K., Kobayashi, T., and Matsuzaka, T. 1971. Fundamental investigations on solidification crack susceptibility for weld metals with Trans-Varestraint test. Trans. of the Japan Welding Society 2(2): 141-162.

30. Hillert, M., and Qiu, C. 1990. A reassessment of the Cr-FeNi system. Metallurgical Transactions A 21(6): 1673-1680. DOI: 10.1007/BF02672583

31. Lubbehusen, M., and Mehrer, H. 1990. Self-diffusion in $\alpha-$ iron: The influence of dislocations and the effect of magnetic phase transition. Acta Metall. Mater. 38(2): 283-292. DOI: 10.1016/ 0956-7151(90)90058-O

32. Bowen, A. W., and Leak, G. M. 1970. Solute diffusion in alpha- and gamma-iron. Metallurgical Transactions 1: 1695-1700.

33. Liu, J., and Kou, S. 2015. Effect of diffusion on susceptibility to cracking during solidification. Acta Materialia 100: 359-368. DOI: 10.1016/j.actamat.2015.08.064

34. Liu, J., and Kou, S. 2016. Crack susceptibility of binary aluminum alloys during solidification. Acta Materialia 110: 84-94. DOI: 10.1016/j.actamat.2016.03.030

35. Liu, J., and Kou, S. 2017. Susceptibility of ternary aluminum alloys to cracking during solidification. Acta Materialia 125: 513-523. DOI: 10.1016/j.actamat.2016.12.028

36. Liu, J., Duarte, H. P., and Kou, S. 2017. Evidence of back diffusion reducing cracking during solidification. Acta Materialia 122: 47-59. DOI: 10.1016/j.actamat.2016.09.037

37. Kou, S. 2015. A criterion for cracking during solidification. Acta Materialia 88: 366-374. DOI: 10.1016/j.actamat.2015.01.034

38. Kou, S. 2015. A simple index for predicting the susceptibility to solidification cracking. Welding Journal 94(12): 374-s to 388-s.

39. Fu, J. W., Yang, Y. S., Guo, J. J., Ma, J. C., and Tong, W. H. 2009. Formation of two-phase coupled microstructure in AISI 304 stainless steel during directional solidification. Journal of Materials Research 24(7): 2835-2840. DOI: 10.1557/jmr.2009.0282

40. Fu, J. W., and Yang, Y. S. 2013. Origin of the lathy ferrite in AISI 304 stainless steel during directional solidification. Journal of Alloys and Compounds 580: 191-194. DOI: 10.1016/j.jallcom.2013. 05.107

41. Fu, J., Sun, J., Cen, X., Zhang, X., Li, F., and Wu, Y. 2018. Growth behavior and orientation relationships in AISI 304 stainless steel during directional solidification. Materials Characterization 139: 241-248. DOI: 10.1016/j.matchar.2018.03.015

42. Lippold, J. C., and Savage, W. F. 1979. Solidification of austenitic stainless steel weldments: Part I-A proposed mechanism. Welding Journal 58(12): 362-s to 374-s.

43. Kannengiesser, T., and Boellinghaus, T. 2014. Hot cracking tests - An overview of present technologies and applications. Weld- 
ing in the World 58(3): 397-421. DOI: 10.1007/s40194-014-0126-y

44. Coniglio, N. 2008. Aluminum alloy weldability: Identification of weld solidification cracking mechanisms through novel experimental technique and model development. Doctoral thesis, Otto von Guericke University, Magdeburg, Berlin.

45. Coniglio, N., Cross, C. E., Michael, T., and Lammers, M. 2008. Defining a critical weld dilution to avoid solidification cracking in aluminum. Welding Journal 87(8): 237-s to 247-s.

46. Bakir, N., Gumenyuk, A., and Rethmeier, M. 2018. Investigation of solidification cracking susceptibility during laser beam welding using an in-situ observation technique. Science and Technology of Welding and Joining 23(3): 234-240. DOI: 10.1080/ 13621718.2017.1367550

47. Soysal, T., and Kou, S. 2020. Role of liquid backfilling in reducing solidification cracking in aluminum welds. Science and Technology of Welding and Joining 25(5): 415-421. DOI: 10.1080/ 13621718.2020.1732054

48. Kou, S., and Le, Y. 1982. The effect of quenching on the solidification structure and transformation behavior of stainless steel welds. Metallurgical Transactions A 13(7): 1141-1152. DOI: 10.1007/ BF02645495

49. Inoue, H., Koseki, T., Okita, S., and Fuji, M. 1997. Solidifica- tion and transformation behaviour of austenitic stainless steel weld metals solidified as primary ferrite: Study of solidification and subsequent transformation of $\mathrm{Cr}-\mathrm{Ni}$ stainless steel weld metals ( $2^{\text {nd }}$ Report). Welding International 11(12): 937-949.

50. Inoue, H., Koseki, T., Ohkita, S., and Fuji, M. 2000. Formation mechanism of vermicular and lacy ferrite in austenitic stainless steel weld metals. Science and Technology of Welding and Joining 5(6): 385-396. DOI: 10.1179/136217100101538452

51. Brooks, J. A., and Garrison, W. M. 1999. Weld microstructure development and properties of precipitation-strengthened martensitic stainless steels. Welding Journal 78(8): 280-s to 291-s.

KUN LIU is a lecturer at the School of Materials Science and Engineering in Jiangsu University of Science and Technology, Zhenjiang, China. PING YU is the former assistant scientist, and SINDO KOU (kou@engr.wisc.edu) is a professor at the Department of Materials Science and Engineering, University of Wisconsin, Madison, Wis.

\section{AWS American Welding Society}

\section{Welding Journal Now Publishing Direct Object Identifier (DOI) Numbers}

Dear members of the welding research community,

Note that in each issue of the Welding Journal Research Supplement, we are including Direct Object Identifier (DOI) numbers with each of the papers published in print and online. A direct object identifier is a unique alphanumeric string assigned by a registration agency (we are using Crossref.org) to identify content and provide a persistent link to its location on the Internet. Our decision to begin assigning a DOI for each paper comes directly from a request by the research community.

As part of our obligation to Crossref.org, we are asked to provide DOI numbers, when available, in the references section of papers. So, if you have submitted a paper to the Welding Journal or are planning on submitting a paper, we ask that you update your references to include DOI numbers whenever possible.

Thank you.

Annette Alonso

Publisher, Welding Journal 